\title{
Interpain A, a Cysteine Proteinase from Prevotella intermedia, Inhibits Complement by Degrading Complement Factor C3
}

\author{
Michal Potempa ${ }^{1,2}$, Jan Potempa ${ }^{2,3}$, Tomasz Kantyka², Ky-Anh Nguyen ${ }^{4}$, Katarzyna Wawrzonek ${ }^{2}$, \\ Surya P. Manandhar ${ }^{4}$, Katarzyna Popadiak ${ }^{1,2}$, Kristian Riesbeck ${ }^{5}$, Sigrun Eick ${ }^{6}$, Anna M. Blom ${ }^{1 *}$
}

1 Lund University, Department of Laboratory Medicine, Section of Medical Protein Chemistry, University Hospital Malmö, Malmö, Sweden, 2 Jagiellonian University, Department of Microbiology, Krakow, Poland, 3 University of Georgia, Department of Biochemistry and Molecular Biology, Athens, Georgia, United States of America, 4 Westmead Millennium Institute, Institute of Dental Research, Sydney, Australia, $\mathbf{5}$ Lund University, Department of Laboratory Medicine, Section of Medical Microbiology, University Hospital Malmö, Malmö, Sweden, 6 Department of Medical Microbiology, University Hospital of Jena, Jena, Germany

\begin{abstract}
Periodontitis is an inflammatory disease of the supporting structures of the teeth caused by, among other pathogens, Prevotella intermedia. Many strains of $P$. intermedia are resistant to killing by the human complement system, which is present at up to $70 \%$ of serum concentration in gingival crevicular fluid. Incubation of human serum with recombinant cysteine protease of $P$. intermedia (interpain A) resulted in a drastic decrease in bactericidal activity of the serum. Furthermore, a clinical strain 59 expressing interpain A was more serum-resistant than another clinical strain 57 , which did not express interpain $A$, as determined by Western blotting. Moreover, in the presence of the cysteine protease inhibitor E64, the killing of strain 59 by human serum was enhanced. Importantly, we found that the majority of $P$. intermedia strains isolated from chronic and aggressive periodontitis carry and express the interpain A gene. The protective effect of interpain A against serum bactericidal activity was found to be attributable to its ability to inhibit all three complement pathways through the efficient degradation of the $\alpha$-chain of C3-the major complement factor common to all three pathways. $P$. intermedia has been known to co-aggregate with $P$. gingivalis, which produce gingipains to efficiently degrade complement factors. Here, interpain A was found to have a synergistic effect with gingipains on complement degradation. In addition, interpain A was able to activate the C1 complex in serum, causing deposition of C1q on inert and bacterial surfaces, which may be important at initial stages of infection when local inflammatory reaction may be beneficial for a pathogen. Taken together, the newly characterized interpain A proteinase appears to be an important virulence factor of $P$. intermedia.
\end{abstract}

Citation: Potempa M, Potempa J, Kantyka T, Nguyen K-A, Wawrzonek K, et al. (2009) Interpain A, a Cysteine Proteinase from Prevotella intermedia, Inhibits Complement by Degrading Complement Factor C3. PLoS Pathog 5(2): e1000316. doi:10.1371/journal.ppat.1000316

Editor: Ulrich von Pawel-Rammingen, Umeå University, Sweden

Received August 8, 2008; Accepted January 28, 2009; Published February 27, 2009

Copyright: (C) 2009 Potempa et al. This is an open-access article distributed under the terms of the Creative Commons Attribution License, which permits unrestricted use, distribution, and reproduction in any medium, provided the original author and source are credited.

Funding: This work was supported by the Swedish Foundation for Strategic Research, the Swedish Research Council, Österlund Foundation, Kock Foundation, King Gustav Vth's 80th Anniversary Foundation, Knut and Alice Wallenberg Foundation, Inga-Britt and Arne Lundberg Foundation, and research grants from the University Hospital in Malmö (to AB), and grants from the Ministry of Science and Higher Education (1642/B/P01/2008/35, Warsaw, Poland) and the National Institutes of Health (DE 09761, United States, to JP). Funding agencies had no influence in the design and conduct of the study, in the collection, analysis, and interpretation of the data, and in the preparation, review, or approval of the manuscript.

Competing Interests: The authors have declared that no competing interests exist.

*E-mail: Anna.Blom@med.lu.se

\section{Introduction}

Periodontitis is an inflammatory condition with an infective etiology that leads to loss of tooth support. Prevotella intermedia is a major bacterial periodontal pathogen in humans together with Porphyromonas gingivalis and Aggregatibacter actinomycetemcomitans [1]. P. intermedia is often recovered from subgingival plaque in patients suffering from acute necrotising gingivitis, pregnancy gingivitis and chronic periodontitis [2]. Recently, $P$. intermedia was reported to be found in $14 \%$ of adult population in Finland and there was association between the carriage of this species and the number of teeth with deepened periodontal pockets [3]. P. intermedia was also frequently isolated from root canal infections [4]. Periodontitis is one of the most common diseases affecting humans and is primarily the result of colonization of the subgingival surfaces of teeth by bacteria. The complex interaction between these bacteria harboring many virulence factors and the host's immune response results in localized chronic inflammation and subsequent destruction of the supporting structures of the tooth. Proteinases are crucial virulence factors produced by many periodontal pathogens, which can cause the degradation of host proteins for essential nutrients but they can also protect the bacteria from the host's defenses such as the complement system $[5,6]$.

Complement is a major arm of the innate immune defense system and its main function is to recognize and destroy microorganisms [7]. The three pathways of human complement ensure that virtually any non-host surface is recognized as hostile. The classical pathway is usually mediated by binding of the $\mathrm{C} 1$ complex (composed of recognition molecule $\mathrm{Clq}$ and two proteinases $\mathrm{Cls}$ and $\mathrm{Clr}$ ) to invading pathogens either directly or via immunoglobulins. The lectin pathway is able to recognize, via mannose-binding lectin (MBL), polysaccharide molecules normally present only on microbial surfaces. Finally, complement can also be activated through the alternative pathway, which is not so much an activation 


\section{Author Summary}

Prevotella intermedia is one of the bacterial pathogens that has been implicated in causing periodontitis-an endemic inflammatory disease of the supporting structures of the teeth. The complement system is an important part of host innate immunity and is able to directly kill invading bacteria. To become successful pathogens, many strains of $P$. intermedia developed mechanisms making them very resistant to killing by complement. We found that a cysteine protease, interpain $A$, that is produced by many clinical strains of $P$. intermedia was able to destroy the bacterial killing activity of human serum. A strain of $P$. intermedia that produces interpain $A$ was found to be more resistant to complement than the one lacking interpain $A$, and the resistance of the interpain A-producing strain could be diminished by a specific inhibitor of cysteine proteases. We attributed the protective effect of interpain A to its ability to inhibit the complement system through the efficient degradation of C3-a major complement protein that is common to all three pathways of complement activation. Understanding the mechanism governing pathogen resistance to complement may help us to design novel therapeutic strategies to prevent or treat an important bacterial disease.

pathway but as a failure to appropriately regulate the constant lowlevel spontaneous activation of C3 (constantly initiated due to inherent instability of this protein). All three pathways lead to opsonisation of the pathogen with C3b (activated form of complement factor C3), which enhances phagocytosis by phagocytes. Furthermore, anaphylatoxins C5a and C3a are released as byproducts to attract phagocytes to the site of infection. Finally, the end result of the complement cascade is formation of the membrane attack complex and bacterial cell lysis. Host cells protect themselves from bystander damage following complement activation through the expression of membrane-bound or recruitment of soluble endogenous complement inhibitors.

Complement deficiencies are very rare but it has been observed that partial C4 gene deficiencies are more frequent in patients with severe chronic periodontitis [8]. A patient with aggressive periodontitis and severe edema, localized to the free gingival tissues was reported to be deficient in C1-inhibitor [9]. Furthermore, the highest salivary levels of C3 were measured in periodontally healthy subjects while low levels were often found in edentulous and chronic periodontitis patients [10].

It has been demonstrated that heat inactivation of NHS (i.e. inactivation of complement) significantly reduced opsonic activity for $P$. intermedia in vitro [11] suggesting that complement is important for host defense against this pathogen. Previous studies have shown that $P$. intermedia was opsonized by the alternative pathway in the absence of the classical pathway, probably in response to the endotoxin [12], however, kinetic studies revealed that opsonisation proceeded at significantly faster rates when the classical pathway was intact [11]. Interestingly, the alternative pathway contributed to the killing of serum sensitive strains while the classical pathway was primarily responsible for killing of strains with intermediate sensitivity [13]. Therefore, it appears that complement is able to recognize $P$. intermedia via several sensory molecules. However, it appears that $P$. intermedia is able to override to some extent the complement defenses and to establish chronic infections in the oral cavity.

Every successful human pathogen must develop means to circumvent complement. Many bacteria are able to capture human complement inhibitors such as C4b-binding protein and factor $\mathrm{H}$ thereby inhibiting complement and avoiding opsonisation and lysis [14-16]. Herpes viruses, on the other hand, produce their own homologues of complement inhibitors [17]. Furthermore, many bacteria use proteinases to incapacitate components of the complement system. For example, most strains of $P$. gingivalis are resistant to bacteriolytic activity of human serum [13,18] and the gingipain proteinases have been implicated as the major factor providing protection against complement in serum [5,19-22]. For a number of Prevotella subspecies and strains, including P. intermedia, the level of proteolytic activity for clinical strains was significantly higher than that recorded for commensal strains isolated from healthy mouths [23]. This, we hypothesize, may provide $P$. intermedia with serum protection.

We have identified three cysteine proteinases in the genome of $P$. intermedia that appeared to be homologues of $\mathrm{SpeB}$ protein of Streptococcus pyogenes [24]. Recently, the first of these genes coding for interpain A (InpA; locus PIN0048) was studied in more detail and its 3D structure was determined [25]. Based on similarity of primary and tertiary structures to known proteinases, InpA is now classified into clan CA, family $\mathrm{C} 10$ and registered in the peptidase database MEROPS ([26]; http://merops.sanger.ac.uk). InpA is a secreted protein composed of 868 amino acid residues including a 44-residue signal peptide, a pro-domain (Ala1-Asn 111), a catalytic domain (Vall 12-Pro359) and a 465-residue C-terminal extension arranged in domains with putative regulatory and secretory functions. However, the specific target(s) and function of InpA have yet to be characterized. In the present study, we have examined in detail the effect of InpA on the human complement system and found that this proteinase targets mainly the C3 component, thereby inhibiting all three complement pathways simultaneously.

\section{Results}

inpA gene is present in the majority of the clinical isolates of $P$. intermedia

In order to estimate what fraction of $P$. intermedia strains found in periodontitis carry the impA gene, detection by PCR was used on subgingival plaque samples obtained from 24 and 58 patients with chronic and aggressive periodontitis, respectively. We have validated specificity of the PCR assay by investigating 25 samples that were negative for $P$. intermedia but rich in other periodontal pathogens. No positive signal was obtained in any of the tested Prevotella-negative samples showing that the assay is specific for Prevotella inpA gene (data not shown). P. intermedia was detected in $33 \%$ and $57 \%$ of plaque samples from chronic and aggressive periodontitis, respectively (Table 1 ). The majority of $P$. intermediapositive samples also yielded positive results regarding the inpA gene implying that InpA fulfils some important physiological function. Similarly, we found that the majority of cultivated $P$. intermedia strains from various sources also express InpA at the protein level as shown by Western blotting analysis of culture supernatants (Figure 1A). The upper band recognized by the specific antibody corresponds to an unprocessed form of InpA while the lower bands are products of autocatalytic processing [25]. Western blotting of lysates of bacterial cells did not yield a signal implying that InpA is mainly secreted by the bacteria and does not associate in large amounts with cell wall in the strains tested (data not shown).

Furthermore, we have detected InpA protein in gingival crevicular fluid samples collected from four chronic periodontitis patients characterized with regard to pocket depth and bleedingon-probing. The samples were analyzed for the $P$. intermedia load 
Table 1. Prevalence of Prevotella intermedia and the presence of interpain A in subgingival plaque samples.

\begin{tabular}{llll}
\hline Group (Numbers) & Prevalence & High Load $\left(\geq \mathbf{1 0}^{\mathbf{6}}\right)$ & inpA Gene Present \\
\hline Healthy controls & 0 & 0 & 6 of $8(75 \%)$ \\
Aggressive periodontitis (24) & $8(33 \%)$ & $3(13 \%)$ & 25 of $31(81 \%)$ \\
\hline Chronic periodontitis (58) & $33(57 \%)$ & $22(38 \%)$ & \\
\hline
\end{tabular}

doi:10.1371/journal.ppat.1000316.t001
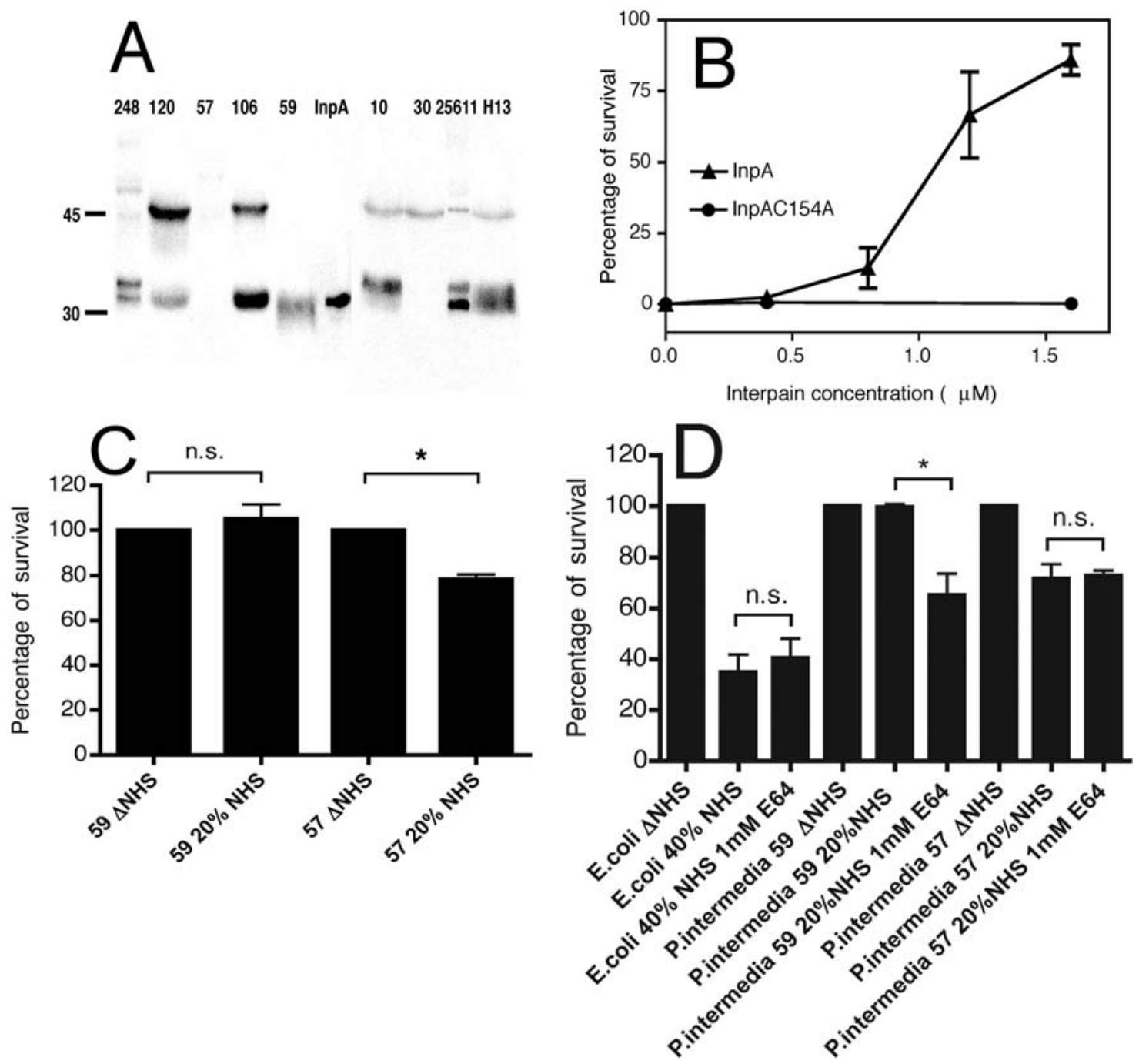

Figure 1. Interpain A destroys bactericidal activity of NHS. (A) Western blotting analysis of InpA expression. Five-day old broth cultures of nine $P$. intermedia strains were adjusted to $\mathrm{OD}_{600}$ of 2 , and the culture supernatants were separated by SDS-PAGE under reducing conditions and proteins transferred onto PVDF membranes. InpA was visualized with polyclonal antibodies. One lane shows purified InpA. (B) Western blotting analysis of gingival crevicular fluid $(20 \mu \mathrm{L} /$ lane) from patients with chronic periodontitis. Load of $P$. intermedia was determined with qPCR ( $<100$ bacteria/sample "-", 100-1,000 bacteria/sample "+", 10,000-50 000 bacteria/sample " ++", >50,000 bacteria/sample "+++"). The leftmost lane contains $1 \mu \mathrm{g}$ of a purified inactive recombinant mutant, InpAC154A. (C) E. coli DH5 $\alpha$ were incubated with $2 \%$ NHS pretreated with increasing concentrations of InpA and InpAC154A, and the surviving bacteria were enumerated after overnight culture on LB agar plates. As a control, heatinactivated NHS ( $\triangle \mathrm{NHS}$ ) was used, and the survival of bacteria in this condition was set to $100 \%$. (D) P. intermedia and E. coli were incubated with $20 \%$ $\mathrm{NHS}$ and $40 \% \mathrm{NHS}$ for $1.5 \mathrm{~h}$ in anaerobic conditions, respectively, with and without supplementation with $1 \mathrm{mM}$ E64 protease inhibitor, and the surviving bacteria were enumerated after culture onto TSB and LB plates, respectively. In (C) and (D) an average of three independent experiments is presented with bars indicating standard deviation (SD). Statistical significance of observed differences was estimated using Student's t-test; n.s. not significant, ${ }^{*} \mathrm{p}<0.05$.

doi:10.1371/journal.ppat.1000316.g001 
using qPCR and subjected to Western blotting analysis. We detected InpA in various forms in samples obtained from patients with significant load of $P$. intermedia but not from those negative for this pathogen (Figure 1B). The $90 \mathrm{kDa}$ form is the unprocessed full length protein, the $76 \mathrm{kDa}$ and the $40 \mathrm{kDa}$ proteins are processed on the $\mathrm{N}$-terminus and the $\mathrm{C}$-terminus, respectively, while the $28 \mathrm{kDa}$ form is the mature, fully-processed protein. These molecular weights are calculated based on amino acid composition. The $40 \mathrm{kDa}$ form runs in fact as $45 \mathrm{kDa}$ protein $(28 \mathrm{kDa}$ form as $32 \mathrm{kDa}$ protein) upon separation on 12\% SDS-PAGE gel.

\section{Interpain A destroys the bactericidal activity of human serum}

In order to quantitatively assess the effect of purified InpA on the bactericidal activity of human serum, we used an E. coli DH5 $\alpha$ model system whereby cells were incubated with normal human serum (NHS) pretreated with various concentrations of InpA or its inactive mutant (InpAC154A) and surviving cells enumerated by colony counting. InpA was found to be able to destroy the bactericidal activity of human serum in a dose-dependent manner and rescued $E$. coli that are otherwise very sensitive to killing by NHS (Figure 1C). Moreover, $P$. intermedia strains have been known to vary significantly in their ability to resist killing by NHS [13], hence, various strains were investigated to see if there was a relationship between the serum resistance of a given strain and its InpA expression level. By Western blotting, $P$. intermedia strain 59 producing a large amount of InpA was found to have a $100 \%$ survival rate in $20 \%$ NHS while only $78 \%$ of the strain 57 with non-detectable InpA production survived (Figure 1A and 1D). Furthermore, addition of a cysteine proteinase inhibitor E64 to NHS decreased the ability of $P$. intermedia strain 59 to survive while it did not affect the killing of strain 57 or E. coli (Figure 1D). Taken together, the results obtained with both purified InpA and $P$. intermedia strains showed that InpA compromised the bactericidal activity of human serum.

\section{Interpain A destroys complement system in human serum}

In order to understand in detail how InpA destroys the bactericidal activity of NHS, i.e. complement, the enzyme was incubated at various concentrations with human serum and hemolytic assays were used to assess activity of the classical and alternative pathways of complement in the pre-treated sera. InpA was found to be an efficient inhibitor of both pathways, whereas the inactive mutant InpAC154A did not show any inhibition (Figure 2A and 2B). InpA was able to inhibit the classical pathway by $80 \%$ when present at high nanomolar concentrations $(0.5 \mu \mathrm{M})$ while the alternative pathway was inhibited by $80 \%$ at $1.5 \mu \mathrm{M}$ concentration. It should be noted, however, that $10 \%$ serum was used for the alternative pathway hemolytic assay versus $1.25 \%$ for the classical pathway. These concentrations were chosen on a basis of the initial titration and represent conditions in which each assay was most sensitive. The alternative pathway is known to require high concentrations of serum in order to function properly in contrast to the classical pathway that is rapidly activated even at fractions of percent of NHS. Taken together, it appears that InpA is approximately equally able to destroy activity of both the classical and alternative pathways.

\section{Interpain A interferes with all three pathways by degrading mainly C3}

Each complement pathway is composed of several factors activated in a consecutive manner. In order to assess which complement factor(s) were affected by InpA, a microtiter plate-
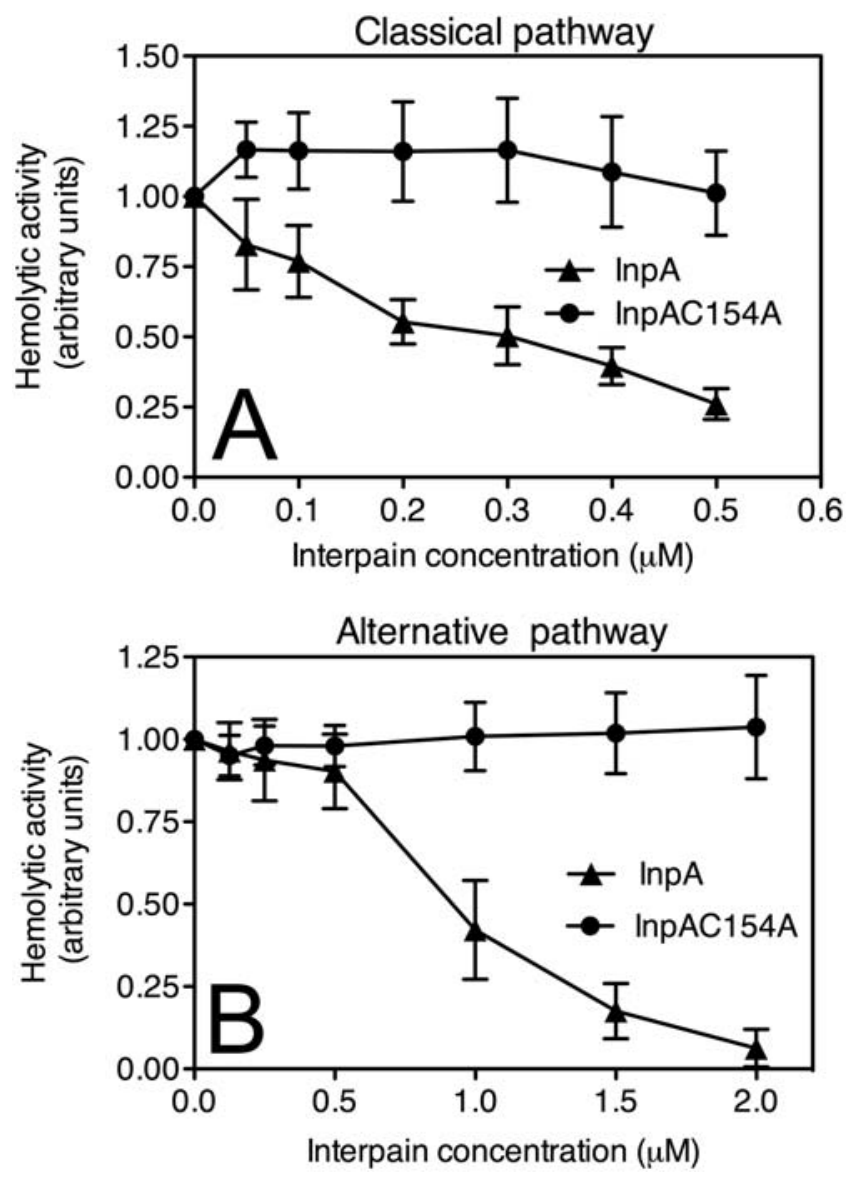

Figure 2. Interpain A destroys hemolytic activity of human serum. Sheep erythrocytes sensitized with antibodies (classical pathway, (A)) or rabbit erythrocytes (alternative pathway, (B)) were incubated with $1.25 \%$ or $10 \%$ NHS, respectively. Serum was supplemented with various concentrations of InpA and InpAC154A. After $1 \mathrm{~h}$ incubation, the degree of lysis was estimated by measurement of released hemoglobin (absorbance at $405 \mathrm{~nm}$ ). Lysis obtained in the absence of interpain was set as 1 . An average of three independent experiments is presented with bars indicating SD.

doi:10.1371/journal.ppat.1000316.g002

based assay in which complement activation was initiated by various ligands depending on the pathway analyzed was used and the deposition of successive complement factors was then detected with specific antibodies. In the case of the classical pathway, complement activation was initiated by immunoglobulin deposition. We found that depositions of $\mathrm{C} 1$ and $\mathrm{C} 4$ from $2 \%$ serum were not affected by InpA (Figure 3A and 3B). However, C3 was found to be sensitive to InpA and deposition of C3b from NHS was abolished at $2 \mu \mathrm{M} \operatorname{InpA}$ (Figure 3C). The inactive InpAC154A mutant had no effect on activation and deposition of C3b at any concentration tested. Accordingly, deposition of C9 that appears in the cascade after C3 was inhibited at similar concentrations as C3 indicating that the inhibitory effect on deposition of C9 was due to degradation of C3 (Figure 3D).

For assessment of the lectin pathway, we used plates bound with mannan carbohydrate. In this case, InpA did not affect the binding of MBL, which is the initiator of the pathway (Figure 4A) and weakly inhibited deposition of C4b (Figure 4B). However, similar to the classical pathway, InpA strongly inhibited the deposition of $\mathrm{C} 3 \mathrm{~b}$ and $\mathrm{C} 9$ while the InpAC154A mutant had no effect (Figure 4C and 4D). 
Classical pathway

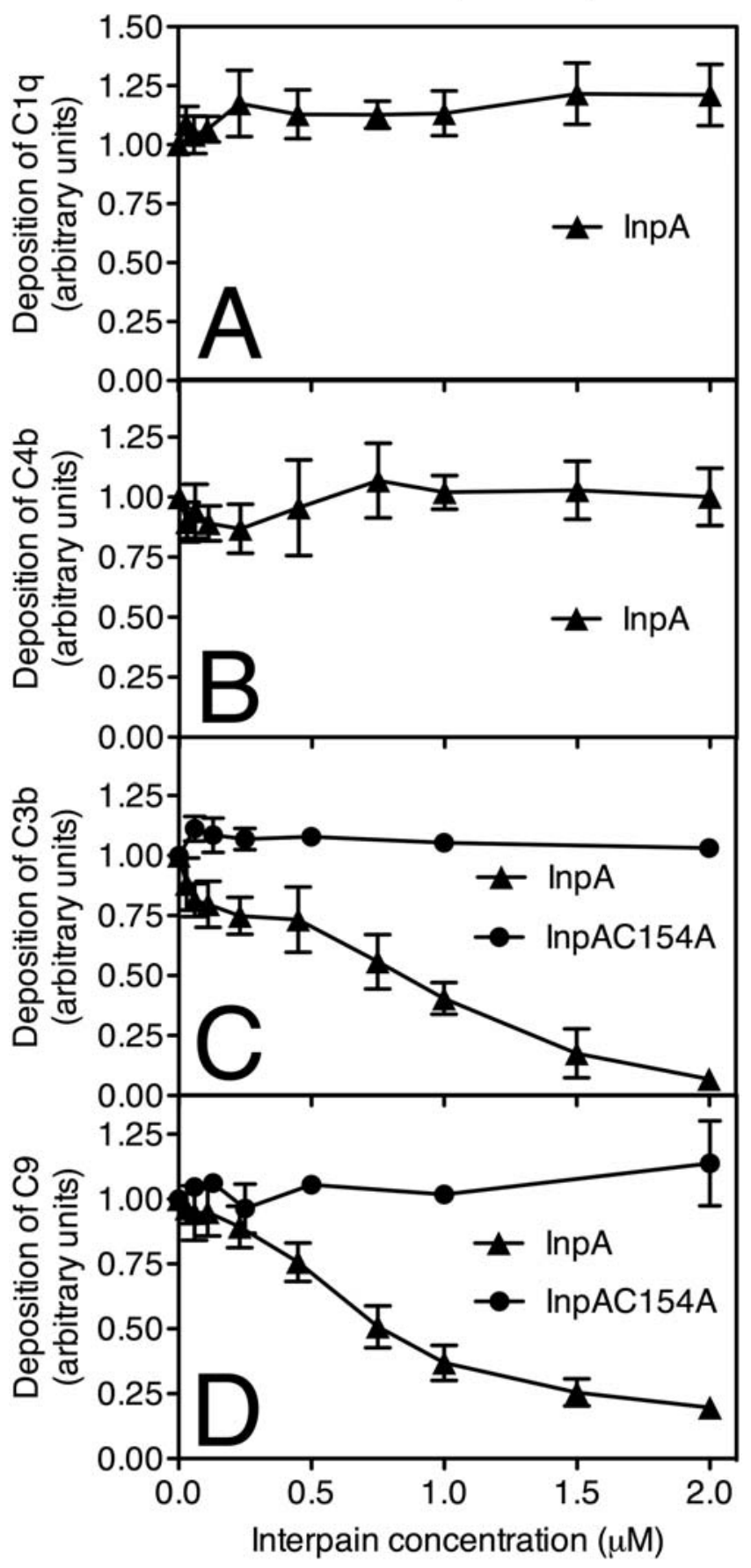

Figure 3. Interpain $\mathbf{A}$ inhibits the classical pathway. $\operatorname{Inp} A$ and InpAC154A were incubated with 2\% NHS (for C1q, C4b, C3b assays) and $10 \%$ NHS (for C9 assay) for 15 min and inactivated with an excess of E64 $(20 \mu \mathrm{M})$ to prevent degradation of IgGs. Human IgGs were immobilized on microtiter plates and allowed to activate NHS pre-incubated with various concentrations of InpA and InpAC154A. After 20 min (C3b, C4b) and $45 \mathrm{~min}(\mathrm{C} 1 \mathrm{q}, \mathrm{C})$ of incubation, the plates were washed, and deposited C1q (A), C4b (B), C3b (C), and C9 (D) were detected with specific polyclonal antibodies. Absorbance obtained in the absence of InpA was set as 1.0 unit. An average of three independent experiments is presented with bars indicating SD. Data points without error bars have minimal SD, which are not displayed by the graphing software (GraphPad Prism 4).

doi:10.1371/journal.ppat.1000316.g003

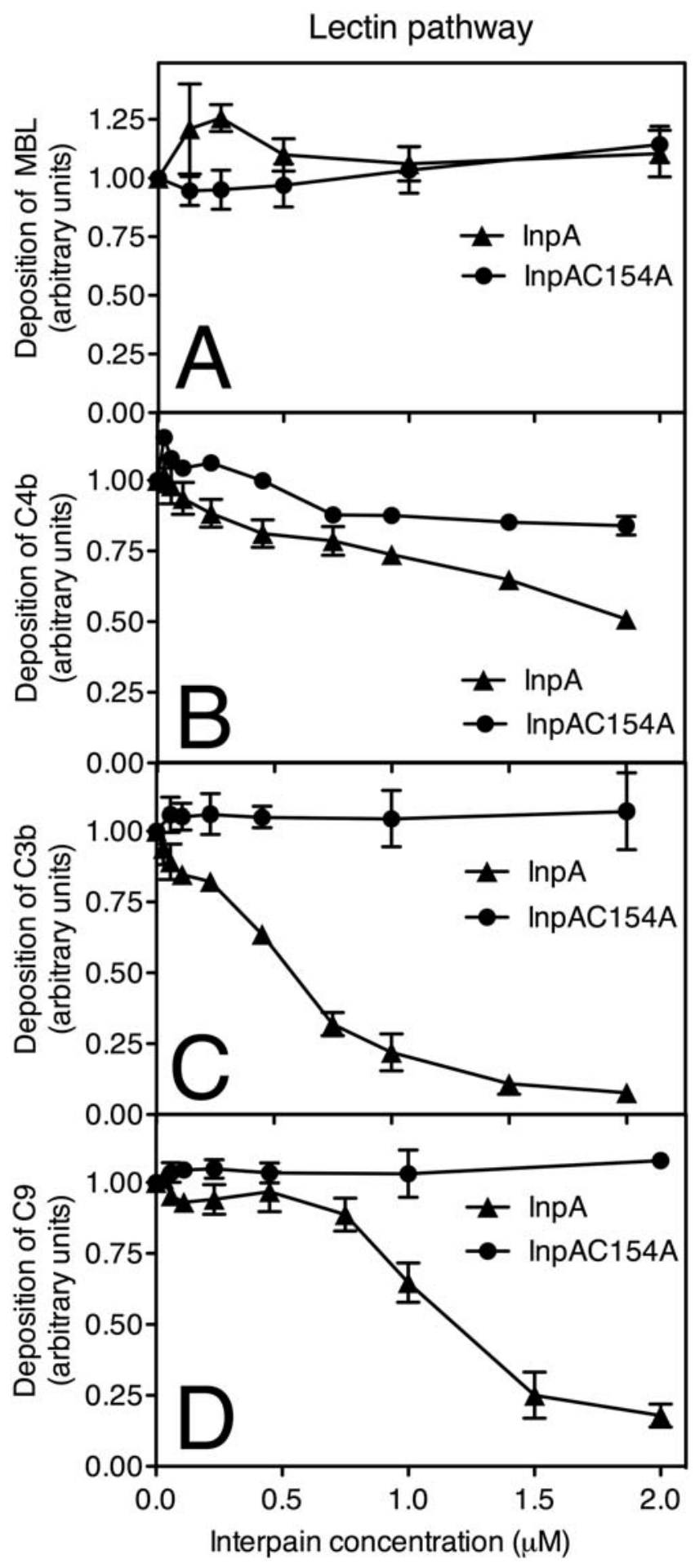

Figure 4. Interpain A inhibits the lectin pathway. Mannan was immobilized on microtiter plates and allowed to activate 4\% NHS (for $\mathrm{MBL}, \mathrm{C} 4 \mathrm{~b}, \mathrm{C} 3 \mathrm{~b}$ assays) and $10 \% \mathrm{NHS}$ (for C9 assay) that was preincubated for $15 \mathrm{~min}$ with various concentrations of $\operatorname{InpA}$ and InpAC154A. After $20 \mathrm{~min}$ (C3b, C4b) and $45 \mathrm{~min}$ (C9, MBL) of incubation, the plates were washed, and deposited MBL (A), C4b (B), $\mathrm{C} 3 \mathrm{~b}(\mathrm{C})$, and $\mathrm{C} 9$ (D) were detected with specific polyclonal antibodies. Absorbance obtained in the absence of interpain was set as 1 . An average of three independent experiments is presented with bars indicating SD.

doi:10.1371/journal.ppat.1000316.g004 
The alternative pathway was activated by immobilized zymosan and InpA was found to be able to inhibit deposition of C3b and C9 with a similar efficiency as previously found for the other two pathways (Figure 5A and 5B). Taken together, all three pathways were sensitive to InpA and its main target appeared to be C3,
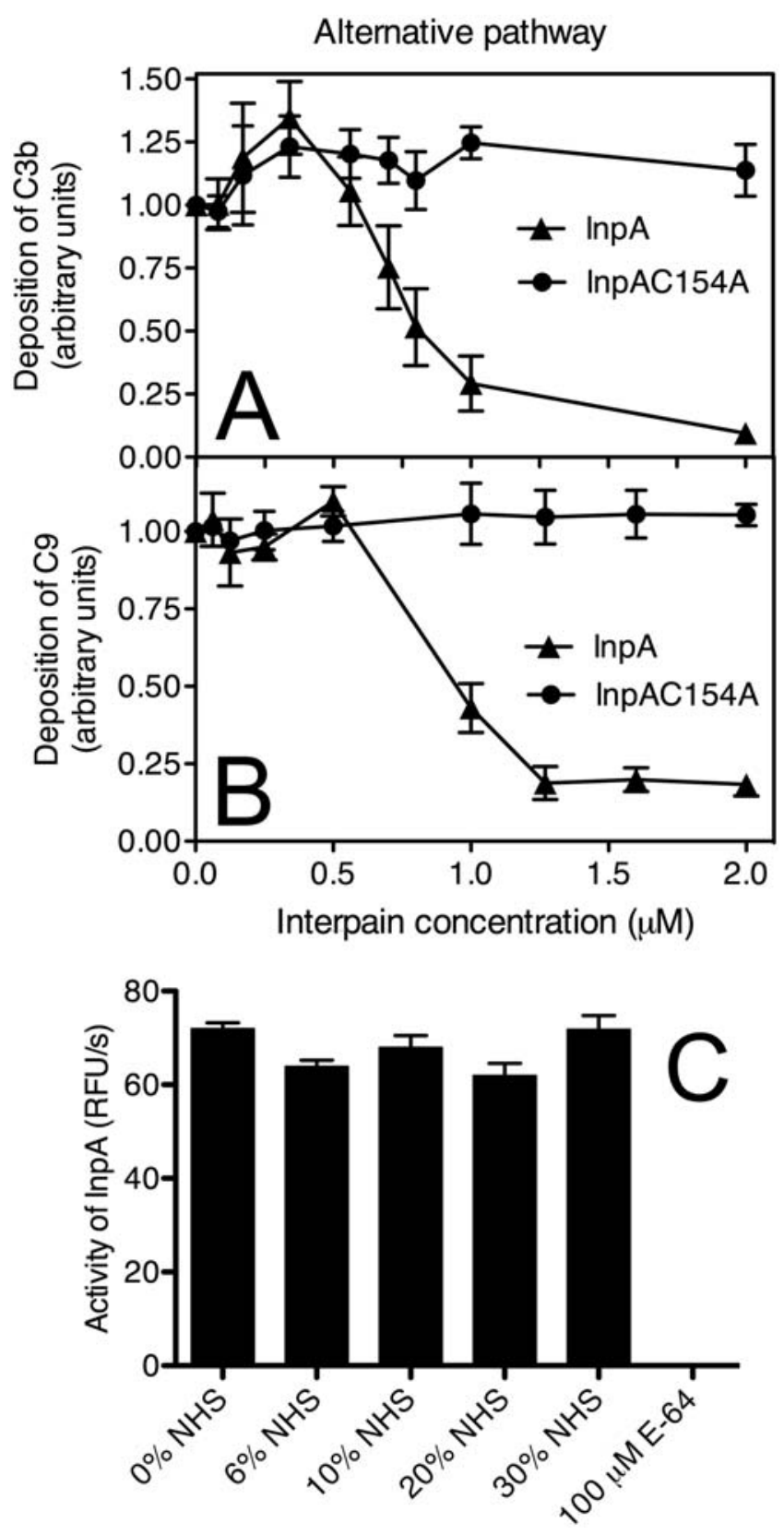

Figure 5. Interpain A inhibits the alternative pathway. Zymosan was immobilized on microtiter plates and allowed to activate $6 \%$ NHS (for C3b assay) and 10\% NHS (for C9 assay) that was pre-incubated for 15 min with various concentrations of InpA and InpAC154A. After $20 \mathrm{~min}$ (C3b) and $45 \mathrm{~min}$ (C9) of incubation, the plates were washed, and deposited $\mathrm{C} 3 \mathrm{~b}$ (A) and $\mathrm{C} 9$ (B) were detected with specific polyclonal antibodies. Absorbance obtained in the absence of interpain was set as 1. (C) InpA was incubated with increasing concentrations of $\mathrm{NHS}$, and the activity of InpA was determined using a synthetic substrate. The cysteine protease inhibitor E64 was used as a control. An average of three independent experiments is presented with bars indicating SD.

doi:10.1371/journal.ppat.1000316.g005 which is the key protein for all pathways of the complement system.

NHS contains several proteinase inhibitors that could potentially inhibit the activity of InpA. However, we found that the InpA activity measured with fluorogenic substrate was not affected by NHS when NHS was present at concentrations up to $30 \%$ (Figure 5C).

Interpain A attacks preferentially $\alpha$-chains of C3 and C4

In order to assess the sites cleaved by InpA, in complement factors, purified C3 and structurally related C4 were incubated with InpA at various molar ratios. The proteins were then separated by SDS-PAGE and visualized using silver staining (Figure 6A and 6B). C3 is composed of covalently linked $\alpha$ - and $\beta$ chains while $\mathrm{C} 4$ contains $\alpha$-, $\beta$ - and $\gamma$-chains. For both proteins, InpA first attacks the $\alpha$-chain while the $\beta$-chain is relatively resistant (Figure 6A-6D); which is similar to what we have previously observed for gingipains [5]. The InpAC154A mutant did not cause any degradation of $\mathrm{C} 3$ or $\mathrm{C} 4$ (Figure $6 \mathrm{~A}$ and $6 \mathrm{~B}$ ). Interestingly, similar concentrations of InpA were required for the degradation of purified C3 and C4, whereas in the presence of NHS, InpA preferentially inactivates C3 (Figures 3 and 4).

To determine sites of proteolysis by InpA, C3 and C4 were treated with InpA and degradation products were separated by SDS-PAGE electrophoresis. The proteins were transferred to PVDF membrane, visualized with Coomassie (Figure 6E) and selected bands were subjected to N-terminal sequencing. Interestingly, cleavage of the C3 polypeptide chain at the site resulting in the N-terminal sequence SNLDEDIIA generated the exact sequence of an anaphylatoxin fragment C3a. Similarly, the cleavage of $\mathrm{C} 4$ producing the $\mathrm{N}$-terminal sequence ALEILQEE generated the exact sequence of C4a. Sequence 2 (SPMYSII) corresponds to the $\mathrm{N}$-terminus of the $\mathrm{C} 3 \beta$-chain.

\section{Kinetic parameters of $\mathrm{C} 3$ and $\mathrm{C} 4$ degradation by interpain $A$}

When degradation of C3 and C4 was assessed at a set concentration of InpA for increasing incubation times, C4 was degraded at a faster rate than C3 (Figure 7A). To determine the kinetic parameters of degradation of $\mathrm{C} 3 \mathrm{~b}$ by InpA, surface plasmon resonance was employed. When the inactive InpAC154A proteinase was injected over immobilized C3b, no change in signal was detected (data not shown). However, upon injection of InpA, there was a rapid decrease in the signal measured in resonance units (RU) corresponding to degradation of $\mathrm{C} 3 \mathrm{~b}$. The initial rates of proteolysis at each concentration of InpA were obtained from the initial slopes in the sensorgrams (Figure 7B). In this system, $1000 \mathrm{RU}$ corresponds to a mass shift of $1 \mathrm{ng} / \mathrm{mm}^{2}$. The analysis demonstrated that $3 \mu \mathrm{M}$ InpA degrades $\mathrm{C} 3 \mathrm{~b}$ at an initial rate of $7 \mathrm{pg} / \mathrm{s}$ (Figure 7B inset). The kinetic parameters of C3 and C4 degradation by InpA were also determined by fitting initial rates of degradation of $\alpha$-chains of C3 and C4 into Michaelis-Menten equation. A constant amount of InpA was incubated with increasing concentrations of $\mathrm{C} 3$ and $\mathrm{C} 4$ and the initial rate of proteolysis at various substrate concentrations was estimated from the decrease of intensity of scanned bands corresponding to $\alpha$ chains of C3 and C4 as resolved by SDS-PAGE. Using this approach, $\mathrm{K}_{\mathrm{m}}$ and $\mathrm{k}_{\mathrm{cat}}$ for $\mathrm{C} 4$ degradation was determined to be $4.3+/-0.8 \mu \mathrm{M}$ and $0.026+/-0.005 \mathrm{~s}^{-1}$, respectively (Figure 7D). Unfortunately, a reasonably accurate measurement of the kinetic constants for C3 was not possible since there was no visible saturation of the initial rate of $\mathrm{C} 3$ degradation up to $2 \mathrm{mg} / \mathrm{mL}$ $(10 \mu \mathrm{M})$ of substrate, hence, the $\mathrm{K}_{\mathrm{m}}$ could only be estimated as greater than $20 \mu \mathrm{M}$ (Figure $7 \mathrm{C}$ ). 

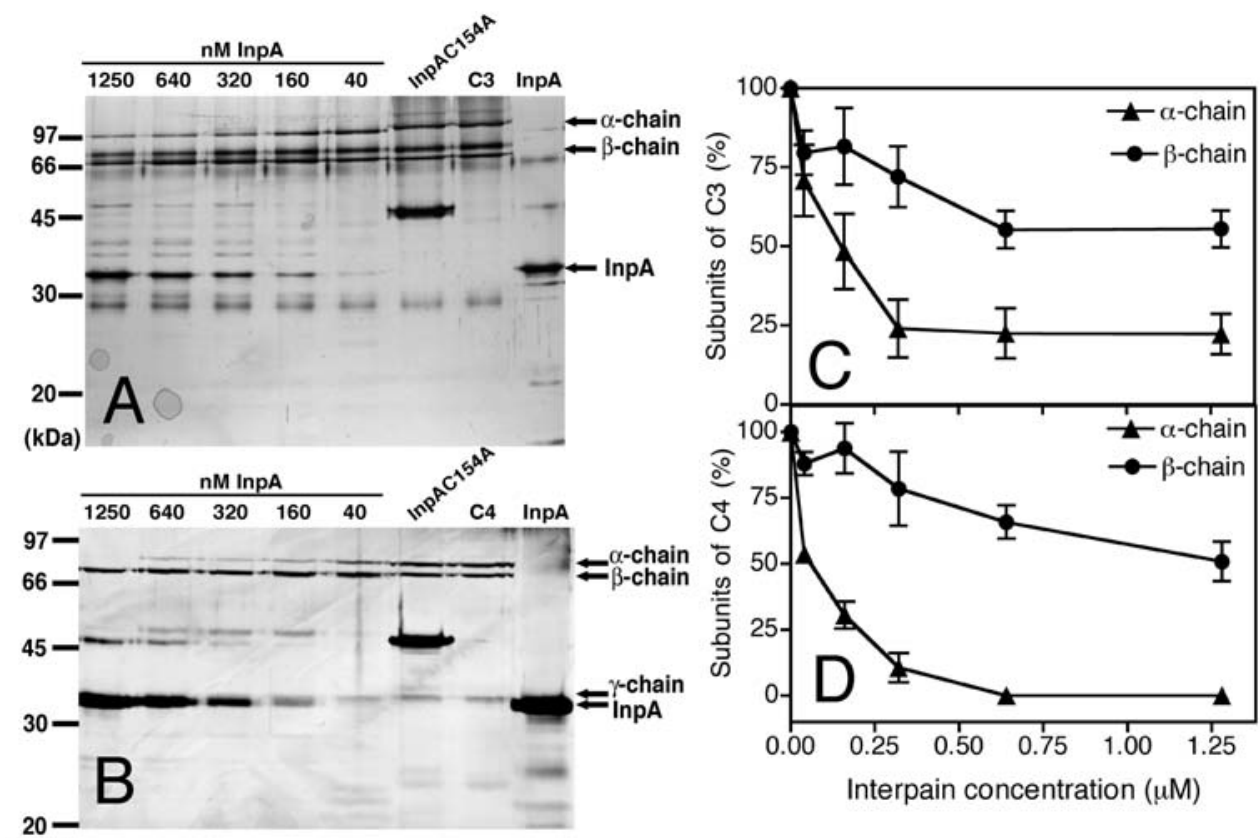

(kDa)

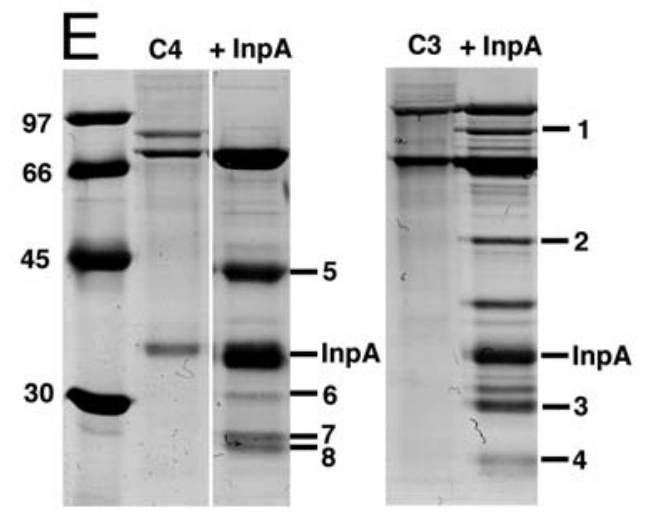

1: SNLDEDI

2: SPMYSII

3: SNLDEDII

4: XAEENXFI

5: ASDPLDTLG

6: ALEILQEE

7: ALEILQEE

8: ALEILQEE

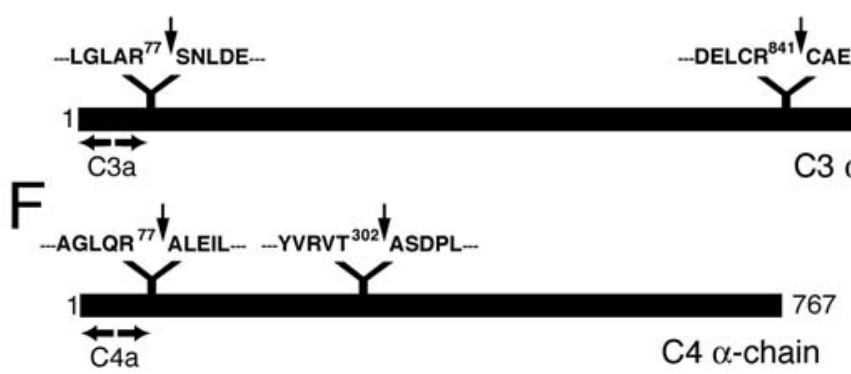

Figure 6. Interpain A degrades preferentially $\boldsymbol{\alpha}$-chains of $\mathbf{C 3}$ and C4. Purified $C 3(A, C)$ and $C 4(B, D)$ were incubated for 30 min with increasing concentrations of InpA or $1250 \mathrm{nM}$ of InpAC154A and separated by SDS-PAGE. The gels were stained with silver $(\mathrm{A}, \mathrm{B})$, and protein band intensities corresponding to the $\alpha$-chains and $\beta$-chains of C3 and C4 were analyzed by densitometry (C,D). The graphs show the $\%$ of native $\alpha$ - and $\beta$-chains remaining after incubation with InpA. An average of three independent experiments is presented with bars indicating SD. (E) In order to determine cleavage sites in $\mathrm{C} 3$ and $\mathrm{C} 4$, these proteins were digested and subjected to $\mathrm{N}$-terminal sequencing. The $\mathrm{N}$-terminal sequences of selected bands are listed on the right. (F) A schematic representation of C3 and C4 $\alpha$-chains with indicated sites of cleavage by InpA. doi:10.1371/journal.ppat.1000316.g006

Interpain A causes activation and deposition of $\mathrm{C} 1$ in the absence of any activator

We have observed previously that gingipains did not degrade C1 but instead were able to cause C1 deposition on surfaces that would not normally activate C1 [5]. In order to assess if this was also the case for InpA, human serum was incubated with InpA in the absence of any immobilized $\mathrm{C} 1$ activator and we observed that it did cause deposition of G1q on the empty microtiter plates blocked with BSA (Figure 8A). In the absence of InpA or in the presence of its inactive mutant, the deposition of $\mathrm{Clq}$ from serum was negligible as expected.

In addition, InpA was also found to be able to cause deposition of $\mathrm{Clq}$ on bacterial surfaces. To this end, Prevotella nigrescens was incubated with NHS containing InpA at different concentrations 

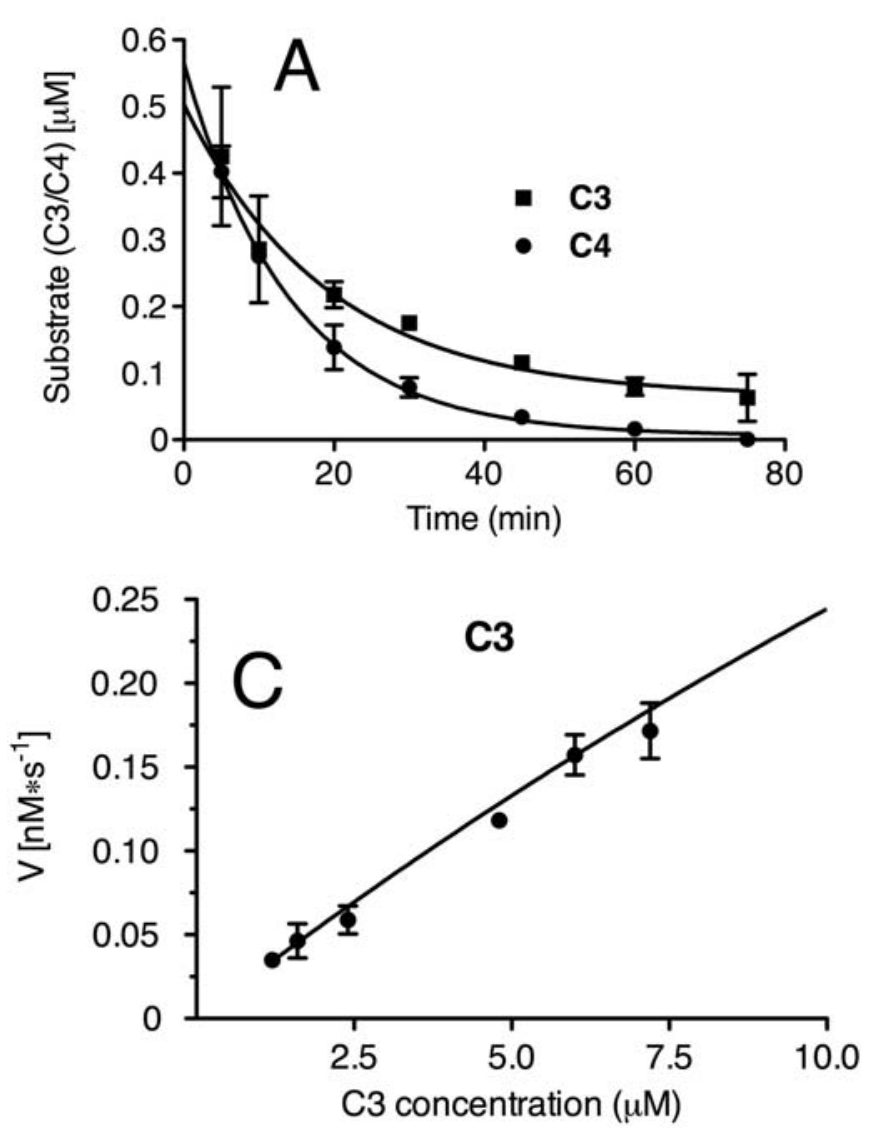
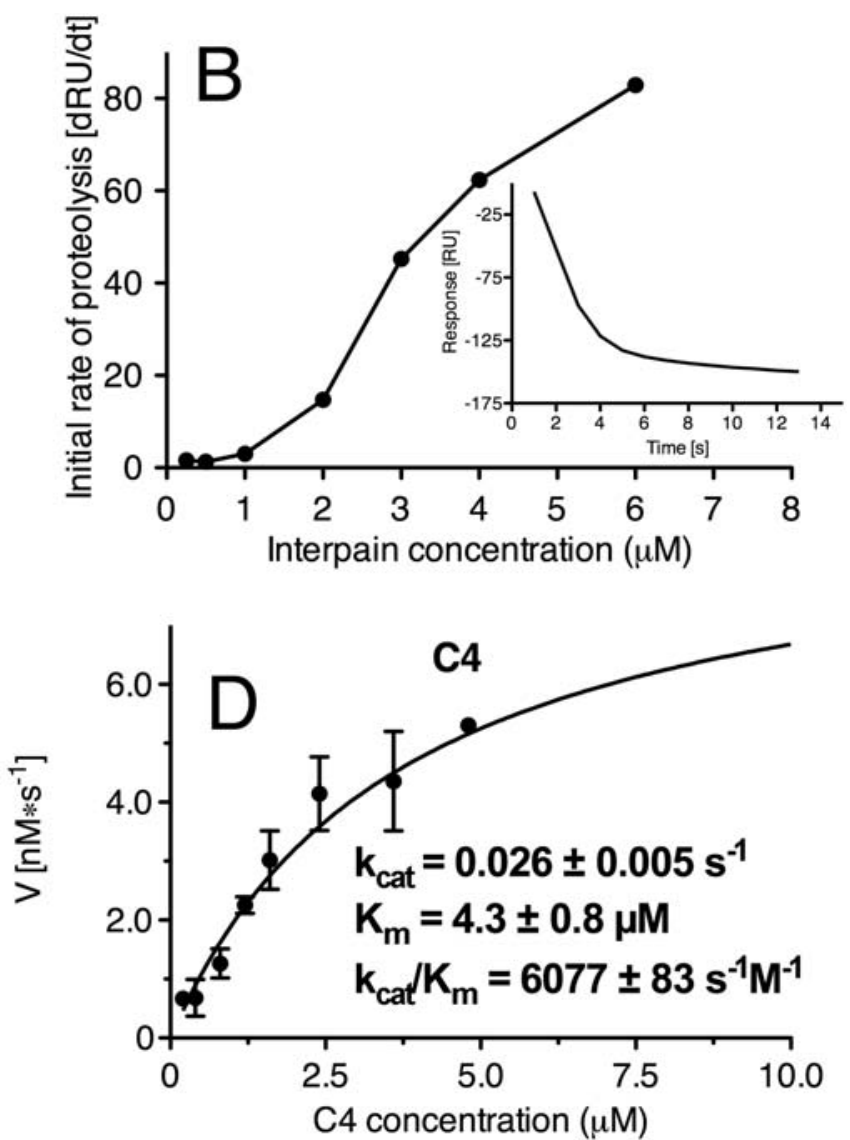

Figure 7. Kinetic parameters of InpA-mediated degradation of C3 and C4. (A) Degradation of C3 and C4 incubated with one concentration of InpA for different time points. (B) Kinetic measurement of degradation of C3b by InpA. Various concentrations of InpA were injected over immobilized C3b, and the reduction in RU values indicates the extent of proteolytic cleavage of C3b. The inset shows a sensorgram obtained for a $3 \mu \mathrm{M}$ InpA sample. The initial rates of proteolysis were determined for each InpA concentration from the slope in the sensorgram and plotted as a function of InpA concentration. (C) Michaelis-Menten plot of degradation of C3 by InpA. InpA was incubated with increasing concentrations of C3, and the amount of remaining $\alpha$-chains (substrate) was determined using densitometry after separation on SDS-PAGE. (D) A similar analysis as in (C) but performed for C4.

doi:10.1371/journal.ppat.1000316.g007

and the deposition of Clq was measured using flow cytometry. We found that addition of InpA to NHS caused an increase in deposition of G1q on the surface of Prevotella that mimicked results obtained using microtiter plates (Figure 8B). Taken together, our results show that InpA is able to cause deposition of active $\mathrm{C} 1$ complex on normally non-activating surfaces such as BSA coated plastic or bacteria. We did not observe degradation of C1q during incubation with InpA, neither when InpA was added to NHS nor when it was incubated with purified Clq (data not shown).

\section{Interpain A acts synergistically with gingipains}

Since InpA and gingipains are often present simultaneously at the sites of infection colonized with $P$. intermedia and $P$. gingivalis, we assessed how they acted on complement when present together. To this end, InpA and the three gingipains (HRgpA and RgpB are arginine-specific gingipains while Kgp is lysine-specific) were preincubated with $4 \%$ NHS at concentrations chosen to affect the activity of the lectin pathway by only $10-30 \%$. The deposition of $\mathrm{C} 3 \mathrm{~b}$ was assessed and we found that the proteinases acted synergistically since the deposition of $\mathrm{C} 3 \mathrm{~b}$ in combinations of InpA and the gingipains was lower than predicted if the effects of the proteinases were added separately (Figure 9). For example, InpA alone decreased the deposition of C3b by $30 \%$ at the concentration used, while Kgp yielded only 25\% decrease. When used together at the same concentrations, InpA and Kgp decreased C3b deposition by $85 \%$ instead of $55 \%$ that would be expected if these proteinases had only additive effects. When all three gingipains were added together with InpA, the deposition of C3b was inhibited by $93 \%$.

\section{Discussion}

Factors governing $P$. intermedia infection are poorly studied when compared to other periodontal pathogens such as $P$. gingivalis. However, it is becoming apparent that all successful human bacterial pathogens must develop strategies to circumvent the complement system [15]. Microorganisms in gingival sulcus are immersed in serum-derived tissue exudate - gingival crevicular fluid, which is similar in composition to human serum. Since complement components are present in gingival crevicular fluid at up to $70 \%$ of serum concentration [27] and in vivo there is high level of complement activation in gingival fluid of patients with periodontitis $[28,29]$, successful evasion of the complement system is paramount for the survival of $P$. intermedia in the periodontal pocket. One such strategy of defense against complement developed by $P$. intermedia appears to depend on the production of InpA, which we now show, is able to degrade complement 

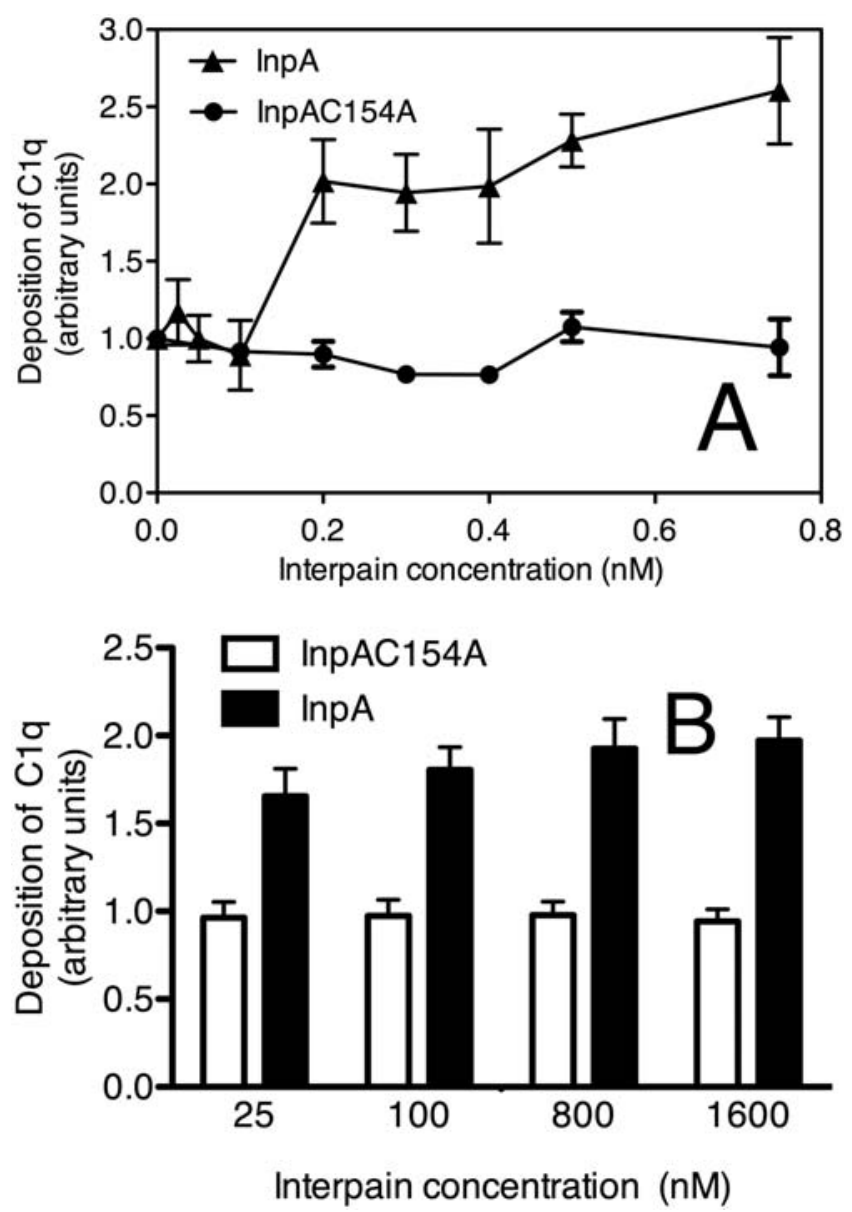

Figure 8. Deposition of C1q on plates and bacteria. (A) Microtiter plates were blocked with BSA and incubated with $4 \%$ NHS containing various concentrations of InpA and InpAC154A for $45 \mathrm{~min}$. Deposited C1q was detected with a specific antibody, and the absorbance obtained in the absence of InpA was set as 1. (B) P. nigrescens ATCC 25261 was incubated with 5\% NHS and different concentrations of InpA and InpAC154A. Deposition of C1q was quantified using flow cytometry with specific FITC-labeled antibodies, and the absorbance obtained in the absence of InpA was set as 1 . An average of three independent experiments is presented with bars indicating SD.

doi:10.1371/journal.ppat.1000316.g008

factor C3, which is the central molecule of the whole complement system. Importantly, the majority of $P$. intermedia strains isolated from aggressive and chronic periodontitis carry and express the inpA gene.

The proteolytic activities of oral bacteria are thought to play important roles in the etiology of periodontitis and dental abscesses. These proteinases may contribute to tissue destruction, increase availability of nutrients and impair host defense by degrading immunoglobulins and components of the complement system. Proteinases of $P$. intermedia display trypsin-like and dipeptidylpeptidase activities [30] and also have the properties of cysteine proteinases [31-33]. They have also been reported to be capable of degrading immunoglobulins, particularly IgG [34,35], fibronectin [36] and host proteinase inhibitors [37]. The degradation of immunoglobulins was mediated mainly by cysteine proteinase(s) [35]. Now we can add C3 to this list.

Importantly, inhibition of C3 function occurred even when InpA was incubated with whole NHS showing that C3 will be specifically degraded even in the presence of all other plasma

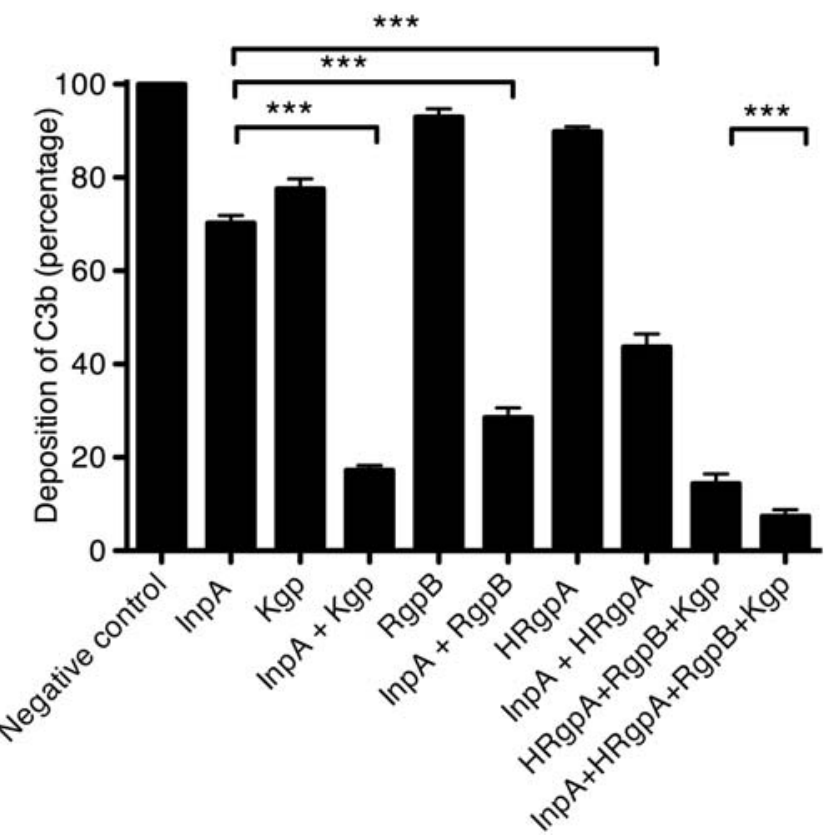

Figure 9. Interpain A and gingipains act synergistically. Mannan was immobilized on microtiter plates and allowed to activate $4 \% \mathrm{NHS}$ containing $350 \mathrm{nM} \operatorname{InpA}$ and three gingipains, Kgp (44 nM), RgpB $(55 \mathrm{nM})$, HRgpA $(33 \mathrm{nM})$, alone or mixed together. After 20 min of incubation, the plates were washed, and deposited $\mathrm{C} 3 \mathrm{~b}$ was detected with specific antibodies. An average of three independent experiments is presented with bars indicating SD. Statistical significance of observed differences was estimated using Student's t-test; ${ }^{* * *} p<0.001$. doi:10.1371/journal.ppat.1000316.g009

proteins (Figures 3-5). This is not the case for C4, which was degraded efficiently when purified proteins were used but its function was only weakly affected in the presence of whole serum. According to kinetic parameters determined with purified proteins, C4 should be a far better target for InpA than C3 in serum. Despite that $\mathrm{C} 4$ in serum seems to be resistant to proteolytic inactivation by InpA. To explain this discrepancy, we speculate that C4 may interact with other protein(s) in serum, which hinders InpA access to a cleavage site. Alternatively, the $\alpha$ chain of C4 may also be susceptible to proteolysis in serum but the cleaved protein is still a functional source of C4b. The latter explanation is supported by the observation that in contrast to C3, proteolysis of C4 is more limited (Figure 6). Such phenomenon has previously been observed for $\alpha_{2}$-macroglobulin, which remained functionally active after cleavage with gingipains [38]. Importantly, it is clear that InpA will affect C3 in a way that it can no longer propagate the complement cascades; which should be of direct benefit to InpA producing $P$. intermedia.

Interestingly, InpA showed a preference for the $\alpha$-chain of C3 and C4, similar to what we have previously observed for gingipains. At low concentrations, gingipains were able to activate complement factors C3, C4 and C5 as they preferentially target the $\alpha$-chains of these proteins to cause the release of anaphylatoxins C3a and C5a as well as the activated forms C3b, C4b and C5b. Similarly, N-terminal sequencing of C3 and C4 fragments generated by InpA revealed that InpA will also release C3a and C4a. At higher concentrations, gingipains simply degrade these three complement factors, particularly C3, into smaller fragments so that they can no longer propagate the complement cascade $[19,39]$. Yet again, we observe a similar phenomenon for InpA in case of C3. Also similar to gingipains, InpA was able to cause the deposition of $\mathrm{C} 1$ from serum onto inert surfaces without the need 
for a specific C1 activator; which may lead to local inflammation. However, whereas this effect could be recreated in vitro using purified C1 for gingipains [5], InpA required serum to be present for this to occur (data not shown). Thus, it appears that InpA may require a third protein to induce $\mathrm{Cl}$ deposition from serum. Consequently, an intricate strategy emerges: periodontal bacteria at low concentrations appear to cause non-specific activation of $\mathrm{Cl}$ and to generate C5a and C3a fragments - chemotactic factors for neutrophils. This may lead to a low grade inflammation that provides access to nutrients for bacterial growth and colonization. At higher concentrations of bacteria and proteinases, the complement system becomes incapacitated by multiple cleavages of critical proteins within the cascade.

$P$. intermedia can be highly resistant to complement and survive at very high serum concentrations but there are significant differences between various strains with regard to sensitivity to killing by complement [13]. In this study, we have shown that there is a correlation between the presence of InpA and serum resistance of $P$. intermedia. Using $E$. coli as a sensitive model to detect bactericidal activity of human serum, we have found that they were able to survive when supplemented with low micromolar concentrations of InpA in the presence of $2 \%$ NHS. In contrast, cells exposed to NHS alone or to NHS containing the inactive interpain mutant showed total loss of viability at this serum concentration. This clearly shows that purified InpA is very efficient at destroying bactericidal activity of NHS. Further, the cysteine proteinase inhibitor E64 diminished serum resistance of $P$. intermedia strains.

It is plausible that $P$. intermedia, in similarity to other bacterial pathogens, has several strategies for evasion of killing by complement. $P$. gingivalis employs not only proteinases for defense from complement [5] but it also produces a surface anionic polysaccharide, the presence of which strongly correlates with exceptional serum resistance of these bacteria [40]. This bacterium also attenuates the effects of complement by capturing human complement inhibitor C4b-binding protein [16]. In this study, we have found that $P$. intermedia was able to retain some of its ability to resist killing even when incubated with serum containing the broad-spectrum inhibitor E64. However, InpA is a secreted protein and we do not expect large amounts of it being present in our bactericidal assay that has been performed within $1.5 \mathrm{~h}$ of culturing. In vivo, the bacteria will have the opportunity to secrete much more interpain into its pericellular environment. Our current methodology does not allow for truly quantitative analysis of the InpA content in gingival crevicular fluid. However, we can estimate from our Western blotting analysis that $20 \mu \mathrm{L}$ of crevicular fluid contained at least $0.1 \mu \mathrm{g}$ of InpA. Taking into account at least 20-fold dilution of crevicular fluid upon collection, the concentration of InpA in the two positive samples analyzed must be greater than $100 \mu \mathrm{g} / \mathrm{mL}$. This corresponds to approximately $4 \mu \mathrm{M}$ of fully processed InpA, implying that the concentration of InpA is high enough for inhibition of the complement system as described to occur in vivo.

Our experiments also showed that InpA will aid survival of bystander bacterial species, thus, creating a favorable condition for the establishment of a common ecosystem that would be a beneficial habitat for all participating species. $P$. intermedia, together with Streptococcus gordonii may be considered to be the early colonizers of tooth surfaces, thereby promoting secondary colonization of pathogenic organisms such as $P$. gingivalis by providing attachment sites, growth substrates and reduced oxygen concentration locally $[41,42]$. P. intermedia belongs to the "orange complex", which encompasses bacterial species bridging between healthy state and advanced periodontitis. Thus, degradation of C3 by InpA in synergy with gingipains of $P$. gingivalis will complement the host immune evasion strategy of subgingival microbiota. Importantly, Prevotella species readily acquire resistance towards antibiotics [43] and deeper knowledge of how infection and serum resistance occur will be crucial for the development of alternative treatments to periodontal disease.

\section{Materials and Methods}

\section{Proteins}

Purified complement proteins were purchased from Complement Technology.

InpA as well as its inactive mutant InpAC154A (the catalytic cysteine was replaced by alanine) were expressed as His-tagged recombinant proteins in Escherichia coli and purified by affinity chromatography on Fast Flow Ni-NTA Sepharose (Qiagen) followed by anion exchange chromatography (MonoQ GE Healthcare) as described previously [25]. The amount of active enzyme in wild-type InpA preparation was determined by active site titration using inhibitor E64 (Sigma). Briefly, recombinant protein was activated at $37^{\circ} \mathrm{C}$ for $15 \mathrm{~min}$ in $0.1 \mathrm{M}$ Tris- $\mathrm{HCl}$, 5 mM EDTA, pH 7.5 freshly supplemented with 2 mM DTT and then preincubated with increasing concentrations of E64 for $37 \mathrm{~min}$ at room temperature. Residual enzyme activity was determined by measurement of fluorescence $\left(\lambda_{\text {ex }}=380 \mathrm{~nm}\right.$ and $\lambda_{\text {em }}=460 \mathrm{~nm}$ ) of AMC released from Boc-Val-Leu-Lys-AMC (PeptaNova) added to the reaction mixture at $250 \mu \mathrm{M}$ final concentration and using the microplate spectrofluorimeter SpectraMax Gemini EM (Molecular Devices). The concentration of active InpA was calculated from the amount of inhibitor needed for total inactivation of the proteinase. The final preparations of wild type InpA and InpAC154A were assayed for possible contamination with lipopolysaccharide using Limulus test (Hycult Biotechnology) and found to contain 7 and $1 \mathrm{ng} / \mathrm{mL}$ lipopolysaccharide, respectively. Arginine-specific (HRgpA and RgpB) and lysine-specific (Kgp) gingipains were purified from the $P$. gingivalis HG66 strain culture fluid as described previously [5]. Before using in any assay, InpA and InpAC154A were preactivated for $15 \mathrm{~min}$ by incubation in a buffer specific for the particular assay supplemented with $2 \mathrm{mM}$ DTT.

\section{Measurement of InpA activity using fluorogenic substrate}

InpA was activated by $15 \mathrm{~min}$ incubation in $0.1 \mathrm{M}$ Tris $\cdot \mathrm{HCl}$, $\mathrm{pH}$ 7.6, $5 \mathrm{mM}$ EDTA, $2 \mathrm{mM}$ DTT at $37^{\circ} \mathrm{C}$. InpA was mixed with increasing concentrations of NHS and incubated for $30 \mathrm{~min}$ at $37^{\circ} \mathrm{C}$. Control samples without serum and with E64 were prepared simultaneously. After incubation, the substrate Boc-ValLeu-Lys-AMC was added to all samples, rendering final volume $200 \mu \mathrm{L}$ and final concentrations of $16.8 \mathrm{nM}$ InpA, 0-30\% NHS, $100 \mu \mathrm{M}$ E64 and 5\% DMSO. Substrate hydrolysis was monitored as AMC release. Activity was determined as the initial velocity of the reaction and expressed in relative fluorescence units (RFU)/s. Results from triplicates were plotted using GraphPad Prism software and calculated as relative activity compared to an uninhibited control.

\section{Bacterial strains and their culture}

For detection of $P$. intermedia in clinical samples, subgingival plaque samples were obtained from patients with severe periodontitis (aggressive periodontitis $(n=24)$, chronic periodontitis $(n=58)$ ). Two paper points were inserted in each pocket for $20 \mathrm{~s}$ and DNA was subsequently extracted using the Genomic Mini system (A\&A Biotechnology) according to the manufacturer's 
recommendations. PCR was carried out using primers: Pi-1: TTT GTT GGG GAG TAA AGG GGG and Pi-2: TCA ACA TCT CTG TAT CGT GCG T [44]. Presence of the inpA gene was determined using PCR with the following primers that were designed based on Oral Pathogen Sequence Database (gene pPI0032; http://www.oralgen.lanl.gov): pPI-1: GAA GGA CAA CTA CAG CGG AAA; pPI-2: TGG TTT CGT TAG TTG GCT GA. Some of the samples were cultivated on Schaedler agar and Schaedler agar supplemented with $7.5 \mathrm{mg} / \mathrm{L}$ vancomycin. Colonies typical for $P$. intermedia were then subcultivated yielding strains 57, 59, 120, 106, BGH10, BGH30, H13 and their identification was confirmed by PGR exactly as described previously [45]. $P$. intermedia OMZ 248 [46], was kindly provided by Dr. Frandsen (Department of Oral Biology, Royal Dental College, Faculty of Health Sciences, University of Aarhus, Denmark). For the experiments conducted in this study, all $P$. intermedia strains were grown on blood-enriched tryptic soy broth (TSB) agar plates at $37^{\circ} \mathrm{C}$ in an anaerobic chamber (Concept 400 , Biotrace) with an atmosphere of $90 \% \mathrm{~N}_{2}, 5 \% \mathrm{CO}_{2}$ and $5 \% \mathrm{H}_{2}$. Escherichia coli laboratory strain $\mathrm{DH} 5 \alpha$ (Invitrogen) and Escherichia coli clinical strain were grown on standard Luria-Bertani (LB) agar plates or in LB broth. Prevotella nigrescens (ATCG 25261) was grown on BBL Columbia II agar containing $8.5 \%$ horse blood, 0.04\% L-cysteine $\mathrm{HCl}, 5 \mathrm{mg} / \mathrm{mL}$ hemin and $2 \mathrm{mg} / \mathrm{mL}$ vitamin $\mathrm{K} 1$. Bacterial strains used in this study are listed in Table 2.

\section{Sampling of crevicular fluid and analysis}

Crevicular washes were obtained using a previously described method from 4 patients with chronic periodontitis. For analysis of P. intermedia presence, DNA was extracted from $5 \mu \mathrm{L}$ of crevicular fluid using the High Pure PCR Template Preparation Kit (Roche) according to the manufacturer's recommendations. Real-time PCR was carried out using a RotorGene 2000 (Corbett Research). Primers specific for $16 \mathrm{~S}$ rDNA from $P$. intermedia were designed as described by [44]. PCR amplification was carried out as described earlier [47]. Determination of InpA in gingival crevicular fluid samples was performed by Western blotting analysis using rabbit polyclonal $\mathrm{Ab}$ against $40 \mathrm{kDa}$ (without C-terminal profragment) form of InpA raised in rabbits by standard immunization with purified recombinant InpAC154A.

Table 2. Description of bacterial strains used in this study.

\begin{tabular}{ll}
\hline Bacterial strain & Characteristics \\
\hline Escherichia coli DH5 $\alpha$ & Common laboratory strain \\
\hline Escherichia coli & $\begin{array}{l}\text { Clinical strain isolated from a patient with } \\
\text { urinary tract infection. }\end{array}$ \\
P. nigrescens (ATCC 25261) & Laryngotomy wound \\
P. intermedia (ATCC 25611) & Empyema \\
$\begin{array}{l}\text { P. intermedia } 59 \\
\text { P. intermedia } 57\end{array}$ & Severe chronic periodontitis \\
P. intermedia OMZ 248 & Severe chronic periodontitis \\
P. intermedia 120 & Severe chronic periodontitis \\
P. intermedia 106 & Aggressive periodontitis \\
P. intermedia BGH 10 & Severe chronic periodontitis \\
P. intermedia BGH 30 & Severe chronic periodontitis \\
P. intermedia H13 & Severe chronic periodontitis \\
\hline doi:10.1371/journal.ppat.1000316.t002
\end{tabular}

\section{Bactericidal assay}

Strain E. coli $\mathrm{DH} 5 \alpha$ was cultured in LB broth until exponential growth phase. Cells were harvested, washed once in $\mathrm{GVB}^{++}$ (5 mM veronal buffer $\mathrm{pH} 7.3,140 \mathrm{mM} \mathrm{NaCl}, 0.1 \%$ gelatin, $1 \mathrm{mM} \mathrm{MgCl}{ }_{2}$ and $0.15 \mathrm{mM} \mathrm{CaCl}{ }_{2}$ ) and adjusted to an optical density at $600 \mathrm{~nm}$ of 0.5 . NHS was prepared from blood taken from six healthy volunteers and pooled. NHS was diluted in $\mathrm{GVB}^{++}$to a concentration of $2 \%$ and incubated with various concentrations of preactivated InpA or InpAC154A for $15 \mathrm{~min}$ at RT. Thereafter, $10^{4}$ bacteria cells were added and incubated with serum supplemented with InpA for $20 \mathrm{~min}$ at $37^{\circ} \mathrm{C}$ in a total volume of $60 \mu \mathrm{l}$. After incubation, aliquots were removed, diluted serially and spread onto LB agar plates. Heat inactivated serum $\left(56^{\circ} \mathrm{C}, 30 \mathrm{~min}\right)$ was used as a negative control. Plates were incubated for $12 \mathrm{~h}$ in $37^{\circ} \mathrm{C}$ after which colonies were counted and percentages of the surviving bacteria were calculated.

$P$. intermedia from four-day old agar plate culture were harvested and washed once in $\mathrm{GVB}^{++}$and adjusted to an optical density at $600 \mathrm{~nm}$ of 0.6 . Thereafter, $2 \times 10^{4}$ bacteria were mixed with $20 \%$ NHS diluted in $\mathrm{GVB}^{++}$and incubated anaerobically for $1.5 \mathrm{~h}$ at $37^{\circ} \mathrm{C}$ in total volume of $110 \mu \mathrm{l}$. The aliquots were removed, diluted serially and spread onto TSB plates. Plates were incubated for 4 days at $37^{\circ} \mathrm{C}$ in an anaerobic chamber after which colonies were counted and percentages of the surviving bacteria were calculated. E. coli were treated in a similar manner except for that $40 \%$ NHS was used. All incubations were performed aerobically and the bacteria were spread on LB agar plates for counting colonies after overnight incubation.

\section{Western blot analysis of interpain $\mathrm{A}$ expression}

P. intermedia strains OMZ 248, 59, 57, 120, 106, BGH 10, BGH 30, H13 and ATCC 25611 were cultured in the Schaedler liquid medium at $37^{\circ} \mathrm{C}$ in an anaerobic chamber for 5 days. Aliquots of cell culture media adjusted to an optical density at $600 \mathrm{~nm}$ of 2.0 were separated under reducing conditions by SDS-PAGE electrophoresis using $12 \%$ gel. The proteins were transferred onto PVDF membrane using semi-dry blotting system. After blocking with $50 \mathrm{mM}$ Tris-HCl, $150 \mathrm{mM} \mathrm{NaCl}, 2 \mathrm{mM} \mathrm{CaCl}, 0.1 \%$ Tween 20 and 3\% fish gelatin, $\mathrm{pH}$ 8.0, InpA was visualized using an anti-InpA polyclonal antibody (1:500 dilution) followed by goat anti-rabbit Abs conjugated to HRP and developed using enhanced chemiluminescence (ECL). The signals were collected using CCD camera (LAS3000, Fujifilm).

\section{Hemolytic assay}

To assess activity of the classical pathway, sheep erythrocytes were washed three times with $\mathrm{DGVB}^{++}$buffer $(2.5 \mathrm{mM}$ veronal buffer $\mathrm{pH} 7.3,70 \mathrm{mM} \mathrm{NaCl}, 140 \mathrm{mM}$ glucose, $0.1 \%$ gelatin, $1 \mathrm{mM} \mathrm{MgCl} 2$ and $\left.0.15 \mathrm{mM} \mathrm{CaCl}_{2}\right)$. The cells were incubated with a complement-fixing antibody (amboceptor; Boehringverke; diluted 1:3000 in $\mathrm{DGVB}^{++}$buffer) at a concentration of $10^{9}$ cells/ $\mathrm{mL}$ for $20 \mathrm{~min}$ at $37^{\circ} \mathrm{C}$. After two washes with $\mathrm{DGVB}^{++}, 5 \times 10^{8}$ cells $/ \mathrm{mL}$ were incubated for $1 \mathrm{~h}$ at $37^{\circ} \mathrm{C}$ with $1.25 \%$ NHS diluted in $\mathrm{DGVB}^{++}$buffer (total volume $200 \mu \mathrm{l}$ ). Before incubation with erythrocytes, NHS was pre-incubated with various concentrations of preactivated InpA or InpAC154A for $15 \mathrm{~min}$ at RT. The buffer used for activation of InpA did not interfere with the hemolytic assay or erythrocytes (data not shown). The samples were centrifuged and the amount of lysed erythrocytes was determined by spectrophotometric measurement of the amount of released hemoglobin (405 nm).

To assess activity of the alternative pathway, rabbit erythrocytes were washed three times with $\mathrm{Mg}^{++}$EGTA buffer $(2.5 \mathrm{mM}$ veronal buffer, containing $70 \mathrm{mM} \mathrm{NaCl}, 140 \mathrm{mM}$ glucose, $0.1 \%$ gelatin, 
$7 \mathrm{mM} \quad \mathrm{MgCl}_{2}, 10 \mathrm{mM}$ EGTA, pH 7.3). Erythrocytes at a concentration of $5 \times 10^{8}$ cells $/ \mathrm{mL}$ were then incubated for $1.5 \mathrm{~h}$ at $37^{\circ} \mathrm{C}$ with $10 \%$ NHS diluted in $\mathrm{Mg}^{++}$EGTA buffer (total volume $200 \mu \mathrm{l})$. NHS used was pre-treated with various concentrations of preactivated InpA or InpAC154A for $15 \mathrm{~min}$ at RT. The samples were centrifuged and the amount of lysed erythrocytes was determined spectrophotometrically.

\section{Complement activation assays}

Microtiter plates (Maxisorp; Nunc) were incubated overnight at $4^{\circ} \mathrm{C}$ with $50 \mu \mathrm{l}$ of a solution containing $2 \mu \mathrm{g} / \mathrm{mL}$ human aggregated IgG (Immuno), $100 \mu \mathrm{g} / \mathrm{mL}$ mannan (Sigma, M7504 ) or $20 \mu \mathrm{g} / \mathrm{mL}$ zymosan (Sigma, Z-4250) in $75 \mathrm{mM}$ sodium carbonate ( $\mathrm{pH}$ 9.6). Between each step of the procedure, the plates were washed four times with $50 \mathrm{mM}$ Tris-HCl, $150 \mathrm{mM} \mathrm{NaCl}$, and $0.1 \%$ Tween $20(\mathrm{pH} 7.5)$. The wells were blocked with $1 \%$ BSA (Sigma) in PBS for $2 \mathrm{~h}$ at RT. NHS was diluted in $\mathrm{GVB}^{++}$ buffer and used at a concentration of $2 \%$ for $\mathrm{C} 3 \mathrm{~b}, \mathrm{C} 4 \mathrm{~b}, \mathrm{C} 1 \mathrm{q}$ (classical pathway), 4\% for C3b, C4b, MBL (lectin pathway), 6\% for $\mathrm{C} 3$ (alternative pathway) and 10\% for C9 (all three pathways). These concentrations were chosen on the basis of initial titrations. NHS was mixed with various concentrations of preactivated InpA or InpAC154A and incubated in the wells of microtiter plates for $45 \mathrm{~min}$ at $37^{\circ} \mathrm{C}$ for $\mathrm{C} 9$ and $\mathrm{MBL}$ and $20 \mathrm{~min}$ at $37^{\circ} \mathrm{C}$ for $\mathrm{C} 3 \mathrm{~b}$ and $\mathrm{C} 4 \mathrm{~b}$ in case of the alternative and the lectin pathways. For the classical pathway, NHS was incubated with preactivated InpA or InpAC154A for $15 \mathrm{~min}$ at RT in eppendorf tubes and the enzyme was inhibited by addition of $20 \mu \mathrm{M}$ E-64 (Calbiochem) to avoid degradation of $\operatorname{IgM}$ deposited on plates. Immediately after addition of inhibitor, NHS was incubated in microtiter plates for $45 \mathrm{~min}$ at $37^{\circ} \mathrm{C}$ for $\mathrm{C} 9$ and $\mathrm{Clq}$ and $20 \mathrm{~min}$ at $37^{\circ} \mathrm{C}$ for $\mathrm{C} 3 \mathrm{~b}$ and C4b. The inhibitor itself did not affect activation of complement at the concentration used (data not shown). Complement activation was assessed by detecting deposited complement factors using rabbit anti-C1q, anti-C4b, anti-C3d polyclonal antibodies (pAbs, DakoCytomation) goat anti-C9 pAb (Complement Technology) and goat anti-MBL $(\mathrm{R} \& \mathrm{D})$ diluted in the blocking buffer. Bound antibodies were detected with HRP-labeled anti-rabbit or antigoat secondary pAb (DakoCytomation). Bound HRP-labelled pAb were detected with 1,2-phenylenediamine dihydrochloride (OPD)tablets (DakoCytomation) and the absorbance was measured at $490 \mathrm{~nm}$.

To assess deposition of purified Clq on microtiter plates without any complement activator, plates were blocked with $1 \%$ BSA in PBS for $2 \mathrm{~h}$ at RT. NHS was diluted in $\mathrm{GVB}^{++}$buffer to $4 \%$ and mixed with various concentration of interpain A. Plates were incubated for $45 \mathrm{~min}$ at $37^{\circ} \mathrm{C}$ with shaking and the deposited $\mathrm{Clq}$ was detected with specific antibodies.

\section{Deposition of C1q on bacteria}

$P$. nigrescens ATCG 25261 from two-day old agar plate cultures were harvested, washed twice in $\mathrm{GVB}^{++}$buffer and adjusted to an optical density at $600 \mathrm{~nm}$ of 1.0. NHS was diluted in $\mathrm{GVB}^{++}$to a concentration of $5 \%$, mixed with $6 \times 10^{5}$ cells and incubated with various concentrations of preactivated InpA or InpAC154A for $30 \mathrm{~min}$ at $37^{\circ} \mathrm{C}$. Thereafter, the cells were washed twice in the binding buffer (10 mM HEPES, $140 \mathrm{mM} \mathrm{NaCl}, 5 \mathrm{mM} \mathrm{KCl}$, $1 \mathrm{mM} \mathrm{MgCl}_{2}, 2 \mathrm{mM} \mathrm{CaCl}_{2}, \mathrm{pH}$ 7.2). Clq deposition was assessed by incubation of the cells with rabbit anti-human $\mathrm{Clq}$ FITC-conjugated polyclonal antibodies (DakoCytomation, diluted in the binding buffer 1:100) for $1 \mathrm{~h}$. The cells were washed twice in the binding buffer and finally resuspended in flow cytometry buffer (50 mM HEPES, $100 \mathrm{mM}$ NaCl, $30 \mathrm{mM} \mathrm{NaN}$, 1\% BSA;
pH 7.4). Flow cytometry analysis was performed using FACS Calibur (Beckton Dickinson).

\section{Degradation assay}

C4 and C3 $(0.8 \mu \mathrm{M}$ each) were incubated with InpA at concentrations ranging from $50 \mathrm{nM}$ to $1250 \mathrm{nM}$. Incubations were carried out in $0.2 \mathrm{M}$ Tris-HCl, $\mathrm{pH} 7.4$, containing $0.1 \mathrm{M} \mathrm{NaCl}$, $5 \mathrm{mM} \mathrm{CaCl}_{2}$ and $2 \mathrm{mM}$ DTT for $30 \mathrm{~min}$ at $37^{\circ} \mathrm{C}$. For the time course experiment, $\mathrm{C} 4$ and $\mathrm{C} 3(0.8 \mu \mathrm{M}$ each) were incubated with $640 \mathrm{nM}$ InpA for 5, 10, 20, 30, 45, 60 and $75 \mathrm{~min}$. The proteins were separated by SDS-PAGE electrophoresis using standard Laemmli procedure and $12 \%$ gels. Prior to electrophoresis the samples were boiled for $5 \mathrm{~min}$ at $95^{\circ} \mathrm{C}$ in a sample loading buffer containing $25 \mathrm{mM}$ DTT and 4\% SDS. After separation, the gels were stained with silver salts to visualize the separated proteins and quantified by densitometry using ImageGauge (FujiFilm, Tokyo, Japan).

\section{N-terminal sequencing}

To determine sites of cleavage by InpA, $10 \mu \mathrm{g}$ of C3 and C4 were incubated with $500 \mathrm{nM}$ preactivated InpA for $2 \mathrm{~h}$ at $37^{\circ} \mathrm{C}$ and the proteins were separated by $12 \%$ SDS-PAGE under reducing condition. The proteins were then transferred to PVDF membranes (Pall) and stained using Coomassie Blue. Bands of interest were excised and analyzed by automated Edman degradation in an Applied Biosystems PROCISE 494 HT sequencer with on-line phenylthiohydantion HPLC analysis using a 140 C Microgradient System from Applied Biosystems, operated according to the manufacturer's recommendations.

\section{Kinetic measurements using surface plasmon resonance (Biacore)}

The analysis was performed according to a previously published protocol [48]. Human C3b was diluted in $10 \mathrm{mM}$ Na-acetate pH 4.0 to a concentration of $30 \mu \mathrm{g} / \mathrm{mL}$ and immobilized on chip CM5 to a level of 3000 RU using amino coupling kit (Biacore) and Biacore 2000. Interpain A was pre-activated by $15 \mathrm{~min}$ activation at $37^{\circ} \mathrm{C}$ in the running buffer $(10 \mathrm{mM}$ HEPES, $150 \mathrm{mM} \mathrm{NaCl}$, $1 \mathrm{mM} \mathrm{MgCl}_{2}, 0.15 \mathrm{mM} \mathrm{CaCl} 2,0.005 \%$ Tween $20,0.2 \mathrm{mM}$ DTT; pH 7.4) with $2 \mathrm{mM}$ DTT and diluted in the running buffer in a concentration range $0.25-6 \mu \mathrm{M}$. Interpain $\mathrm{A}$ was then injected at the flow rate of $5 \mu \mathrm{l} / \mathrm{min}$ at $37^{\circ} \mathrm{C}$ over the immobilized C3met and its activity was quantified as decrease in RU on the sensorgram and analyzed using Biaevaluation software (Biacore).

\section{Determination of kinetic parameters of C3 and C4 degradation by InpA}

Several concentrations of C3 $(1.2-7.2 \mu \mathrm{M})$ and C4 (0.2$4.8 \mu \mathrm{M})$ diluted in $\mathrm{DGVB}^{++}$were incubated with $110 \mathrm{nM}$ or $40 \mathrm{nM}$ of preactivated InpA, respectively. The incubation time was $4 \mathrm{~h}$ and $20 \mathrm{~min}$ for $\mathrm{C} 3$ and $\mathrm{C} 4$, respectively. In parallel, the same concentrations of C3 and C4 were incubated without enzyme. Proteins were separated under reducing conditions by SDS PAGE using $12 \%$ gel, stained with Coomassie and the gels were scanned followed by densitometry determination of $\alpha$-chains of C3 and C4 (ImageGauge). Intensity of $\alpha$-chain bands in the presence of InpA was compared to corresponding controls and expressed as the amount of substrate remaining. Initial velocity of the reaction at each concentration was calculated as amount of substrate consumed within one second and fitted by nonlinear regression into the Michaelis-Menten equation $\mathrm{V}=\left(\mathrm{k}_{\mathrm{cat}} *[\mathrm{E}]_{\mathrm{t}} *[\mathrm{~S}]\right) /$ $\left([\mathrm{S}]+\mathrm{K}_{\mathrm{m}}\right)$ using GraphPad Prism. Values $K_{m}$ and $k_{\text {cat }}$ were obtained as regression curve parameters. Similar values were obtained from two independent experiments. 


\section{Ethics statement}

The ethical board of Lund University has approved collection of sera from healthy human volunteers. The ethical committee of Jena University approved collection of periodontal plaques and crevicular fluid. Informed consent was obtained from patients and the investigation was performed according to principles of the Declaration of Helsinki.

\section{Statistical analysis}

Student's t-test was used to calculate the $\mathrm{p}$ values in order to estimate if the observed differences between experimental results were statistically significant.

\section{References}

1. Darby I, Curtis M (2001) Microbiology of periodontal disease in children and young adults. Periodontol 2000 26: 33-53.

2. Loesche WJ, Syed SA, Laughon BE, Stoll J (1982) The bacteriology of acute necrotizing ulcerative gingivitis. J Periodontol 53: 223-230.

3. Kononen E, Paju S, Pussinen PJ, Hyvonen M, Di Tella P, et al. (2007) Population-based study of salivary carriage of periodontal pathogens in adults. J Clin Microbiol 45: 2446-2451.

4. Tomazinho LF, Avila-Campos MJ (2007) Detection of Porphyromonas gingivalis, Porphyromonas endodontalis, Prevotella intermedia, and Prevotella nigrescens in chronic endodontic infection. Oral Surg Oral Med Oral Pathol Oral Radiol Endod 103: 285-288

5. Popadiak K, Potempa J, Riesbeck K, Blom AM (2007) Biphasic effect of gingipains from Porphyromonas gingivalis on the human complement system. J Immunol 178: 7242-7250.

6. Potempa J, Pike RN (2009) Corruption of innate immunity by bacterial proteases. J Innate Immun, In press.

7. Walport MJ (2001) Complement. First of two parts. N Engl J Med 344: 1058-1066.

8. Seppanen M, Lokki ML, Notkola IL, Mattila K, Valtonen V, et al. (2007) Complement and c4 null alleles in severe chronic adult periodontitis. Scand J Immunol 65: 176-181.

9. Roberts A, Shah M, Chapple IL (2003) C-1 esterase inhibitor dysfunction localised to the periodontal tissues: clues to the role of stress in the pathogenesis of chronic periodontitis? J Clin Periodontol 30: 271-277.

10. Aurer A, Jorgic-Srdjak K, Plancak D, Stavljenic-Rukavina A, Aurer-Kozelj J (2005) Proinflammatory factors in saliva as possible markers for periodontal disease. Coll Antropol 29: 435-439.

11. Tofte RW, Peterson PK, Schmeling D, Bracke J, Kim Y, et al. (1980) Opsonization of four Bacteroides species: role of the classical complement pathway and immunoglobulin. Infect Immun 27: 784-792.

12. Okuda K, Yanagi K, Takazoe I (1978) Complement activation by Propionibacterium acnes and Bacteroides melaninogenicus. Arch Oral Biol 23: 911-915.

13. Sundqvist G, Johansson E (1982) Bactericidal effect of pooled human serum on Bacteroides melaninogenicus, Bacteroides asaccharolyticus and Actinobacillus actinomycetemcomitans. Scand J Dent Res 90: 29-36.

14. Blom AM, Villoutreix BO, Dahlbäck B (2004) Complement inhibitor C4bbinding protein - friend or foe in the innate immune system? Mol Immunol 40: 1333-1346.

15. Zipfel PF, Wurzner R, Skerka C (2007) Complement evasion of pathogens: common strategies are shared by diverse organisms. Mol Immunol 44: 3850-3857.

16. Potempa M, Potempa J, Okroj M, Popadiak K, Eick S, et al. (2008) Binding of complement inhibitor $\mathrm{C} 4 \mathrm{~b}$-binding protein contributes to serum resistance of Porphyromonas gingivalis. J Immunol 181: 5537-5544.

17. Mark L, Spiller OB, Villoutreix BO, Blom AM (2007) Kaposi's sarcomaassociated herpes virus complement control protein: KCP-complement inhibition and more. Mol Immunol 44: 11-22.

18. Okuda K, Kato T, Naito Y, Ono M, Kikuchi Y, et al. (1986) Susceptibility of Bacteroides gingivalis to bactericidal activity of human serum. J Dent Res 65: 1024-1027.

19. Wingrove JA, DiScipio RG, Chen Z, Potempa J, Travis J, et al. (1992) Activation of complement components $\mathrm{C} 3$ and $\mathrm{C} 5$ by a cysteine proteinase (gingipain-1) from Porphyromonas (Bacteroides) gingivalis. J Biol Chem 267: 18902-18907.

20. Grenier D (1992) Inactivation of human serum bactericidal activity by a trypsinlike protease isolated from Porphyromonas gingivalis. Infect Immun 60: 1854-1857.

21. Cutler CW, Arnold RR, Schenkein HA (1993) Inhibition of C3 and IgG proteolysis enhances phagocytosis of Porphyromonas gingivalis. J Immunol 151: 7016-7029.

22. Schenkein HA, Fletcher HM, Bodnar M, Macrina FL (1995) Increased opsonization of a prtH-defective mutant of Porphyromonas gingivalis W83 is caused by reduced degradation of complement-derived opsonins. J Immunol 154: 5331-5337.

\section{Acknowledgments}

Mrs. Margareta Pålsson is acknowledged for expert technical help, Professor Jan Enghild and Mrs. Ida Thogersen for N-terminal sequencing, and Dr. Marcin Okroj for valuable methodological advice.

\section{Author Contributions}

Conceived and designed the experiments: MP JP KAN KR SE AMB. Performed the experiments: MP TK KP SE. Analyzed the data: MP JP TK SE AMB. Contributed reagents/materials/analysis tools: JP KAN KW SPM KR SE AMB. Wrote the paper: MP JP KAN KR SE AMB.

23. Yanagisawa M, Kuriyama T, Williams DW, Nakagawa K, Karasawa T (2006) Proteinase activity of prevotella species associated with oral purulent infection. Curr Microbiol 52: 375-378.

24. Potempa J, Golonka E, Filipek R, Shaw LN (2005) Fighting an enemy within: cytoplasmic inhibitors of bacterial cysteine proteases. Mol Microbiol 57: 605-610.

25. Mallorqui-Fernandez N, Manandhar SP, Mallorqui-Fernandez G, Uson I, Wawrzonek K, et al. (2007) A new autocatalytic activation mechanism for cysteine proteases revealed by Prevotella intermedia interpain A. J Biol Chem 283: $2871-2882$

26. Rawlings ND, Morton FR, Kok CY, Kong J, Barrett AJ (2008) MEROPS: the peptidase database. Nucleic Acids Res 36: D320-D325.

27. Schenkein HA, Genco RJ (1977) Gingival fluid and serum in periodontal diseases. I. Quantitative study of immunoglobulins, complement components, and other plasma proteins. J Periodontol 48: 772-777.

28. Attström R, Laurel AB, Lahsson U, Sjöholm A (1975) Complement factors in gingival crevice material from healthy and inflamed gingiva in humans. J Periodontal Res 10: 19-27.

29. Schenkein HA, Genco RJ (1977) Gingival fluid and serum in periodontal diseases. II. Evidence for cleavage of complement components C3, C3 proactivator (factor B) and C4 in gingival fluid. J Periodontol 48: 778-784.

30. Shibata Y, Miwa Y, Hirai K, Fujimura S (2003) Purification and partial characterization of a dipeptidyl peptidase from Prevotella intermedia. Oral Microbiol Immunol 18: 196-198.

31. Gazi MI, Cox SW, Clark DT, Eley BM (1997) Characterization of protease activities in Capnocytophaga spp., Porphyromonas gingivalis, Prevotella spp., Treponema denticola and Actinobacillus actinomycetemcomitans. Oral Microbiol Immunol 12: 240-248.

32. Guan SM, Nagata H, Shizukuishi S, Wu JZ (2006) Degradation of human hemoglobin by Prevotella intermedia. Anaerobe 12: 279-282.

33. Deschner J, Singhal A, Long P, Liu CG, Piesco N, et al. (2003) Cleavage of CD14 and LBP by a protease from Prevotella intermedia. Arch Microbiol 179: 430-436.

34. Kilian M (1981) Degradation of immunoglobulins A2, A2, and G by suspected principal periodontal pathogens. Infect Immun 34: 757-765.

35. Jansen HJ, Grenier D, Van der Hoeven JS (1995) Characterization of immunoglobulin G-degrading proteases of Prevotella intermedia and Prevotella nigrescens. Oral Microbiol Immunol 10: 138-145.

36. Wikstrom M, Linde A (1986) Ability of oral bacteria to degrade fibronectin. Infect Immun 51: 707-711.

37. Grenier D (1996) Degradation of host protease inhibitors and activation of plasminogen by proteolytic enzymes from Porphyromonas gingivalis and Treponema denticola. Microbiology 142(Pt 4): 955-961.

38. Gron H, Pike R, Potempa J, Travis J, Thogersen IB, et al. (1997) The potential role of alpha 2-macroglobulin in the control of cysteine proteinases (gingipains) from Porphyromonas gingivalis. J Periodontal Res 32: 61-68.

39. Schenkein HA, Berry CR (1988) Production of chemotactic factors for neutrophils following the interaction of Bacteroides gingivalis with purified C5. J Periodontal Res 23: 308-312.

40. Slaney JM, Gallagher A, Aduse-Opoku J, Pell K, Curtis MA (2006) Mechanisms of Resistance of Porphyromonas gingivalis to Killing by Serum Complement. Infect Immun 74: 5352-5361.

41. Nonaka E, Kiyama-Kishikawa M, Hayakawa M (2001) Identification of 40-kDa outer membrane protein as an aggregation factor of Porphyromonas gingivalis to Streptococcus gordonii. J Oral Sci 43: 239-243.

42. Kamaguchi A, Ohyama T, Sakai E, Nakamura R, Watanabe T, et al. (2003) Adhesins encoded by the gingipain genes of Porphyromonas gingivalis are responsible for co-aggregation with Prevotella intermedia. Microbiology 149: 1257-1264

43. Walker CB (1996) The acquisition of antibiotic resistance in the periodontal microflora. Periodontol 2000 10: 79-88.

44. Ashimoto A, Chen G, Bakker I, Slots J (1996) Polymerase chain reaction detection of 8 putative periodontal pathogens in subgingival plaque of gingivitis and advanced periodontitis lesions. Oral Microbiol Immunol 11: 266-273. 
45. Mayanagi G, Sato T, Shimauchi H, Takahashi N (2004) Detection frequency of periodontitis-associated bacteria by polymerase chain reaction in subgingival and supragingival plaque of periodontitis and healthy subjects. Oral Microbiol Immunol 19: 379-385.

46. Gmur R, Thurnheer T (2002) Direct quantitative differentiation between Prevotella intermedia and Prevotella nigrescens in clinical specimens. Microbiology 148: 1379-1387.
47. Puklo M, Guentsch A, Hiemstra PS, Eick S, Potempa J (2008) Analysis of neutrophil-derived antimicrobial peptides in gingival crevicular fluid suggests importance of cathelicidin LL-37 in the innate immune response against periodontogenic bacteria. Oral Microbiol Immunol 23: 328-335.

48. Terao Y, Mori Y, Yamaguchi M, Shimizu Y, Ooe K, et al. (2008) Group A streptococcal cysteine protease degrades $\mathrm{C} 3(\mathrm{C} 3 \mathrm{~b})$ and contributes to evasion of innate immunity. J Biol Chem 283: 6253-6260. 